\title{
Evaluation and projected changes of precipitation statistics in convection-permitting WRF climate simulations over Central Europe
}

\author{
Sebastian Knist ${ }^{1,2,4}$ (D) Klaus Goergen ${ }^{3,4}$ (D) Clemens Simmer $^{1,4}$ (D)
}

Received: 13 August 2017 / Accepted: 15 February 2018 / Published online: 22 February 2018

(c) The Author(s) 2018. This article is an open access publication

\begin{abstract}
We perform simulations with the WRF regional climate model at 12 and $3 \mathrm{~km}$ grid resolution for the current and future climates over Central Europe and evaluate their added value with a focus on the daily cycle and frequency distribution of rainfall and the relation between extreme precipitation and air temperature. First, a 9 year period of ERA-Interim driven simulations is evaluated against observations; then global climate model runs (MPI-ESM-LR RCP4.5 scenario) are downscaled and analyzed for three 12-year periods: a control, a mid-of-century and an end-of-century projection. The higher resolution simulations reproduce both the diurnal cycle and the hourly intensity distribution of precipitation more realistically compared to the $12 \mathrm{~km}$ simulation. Moreover, the observed increase of the temperature-extreme precipitation scaling from the Clausius-Clapeyron (C-C) scaling rate of $\sim 7 \% \mathrm{~K}^{-1}$ to a super-adiabatic scaling rate for temperatures above $11{ }^{\circ} \mathrm{C}$ is reproduced only by the $3 \mathrm{~km}$ simulation. The drop of the scaling rates at high temperatures under moisture limited conditions differs between sub-regions. For both future scenario time spans both simulations suggest a slight decrease in mean summer precipitation and an increase in hourly heavy and extreme precipitation. This increase is stronger in the $3 \mathrm{~km}$ runs. Temperature-extreme precipitation scaling curves in the future climate are projected to shift along the $7 \% \mathrm{~K}^{-1}$ trajectory to higher peak extreme precipitation values at higher temperatures. The curves keep their typical shape of $\mathrm{C}-\mathrm{C}$ scaling followed by super-adiabatic scaling and a drop-off at higher temperatures due to moisture limitation.
\end{abstract}

Keywords Convection-permitting simulation - Regional climate modeling - Added value Climate change projection . Precipitation statistics

This paper is a contribution to the special issue on Advances in Convection-Permitting Climate Modeling, consisting of papers that focus on the evaluation, climate change assessment, and feedback processes in kilometer-scale simulations and observations. The special issue is coordinated by Christopher L. Castro, Justin R. Minder, and Andreas F. Prein.

Sebastian Knist

sknist@uni-bonn.de

Klaus Goergen

k.goergen@fz-juelich.de

Clemens Simmer

csimmer@uni-bonn.de

1 Meteorological Institute, University of Bonn, Meckenheimer Allee 176, 53115 Bonn, Germany

2 Jülich Supercomputing Centre, Research Centre Jülich, Wilhelm-Johnen-Straße, 52428 Juelich, Germany

3 Agrosphere (IBG-3), Research Centre Jülich, Wilhelm-Johnen-Straße, 52428 Jülich, Germany

4 Centre for High-Performance Scientific Computing in Terrestrial Systems, Geoverbund ABC/J, Jülich, Germany

\section{Introduction}

The correct representation of sub-daily precipitation amounts in regional climate models (RCMs) is of high importance since extreme precipitation events, which often evolve over sub-daily to hourly time scales, can cause severe natural hazards, like flash floods affecting urban areas and small river catchments. Such short-term events usually develop also over small space scales and are related to convective precipitation. Accordingly, higher horizontal grid resolutions in RCMs better capture the dynamics of such events and improve simulated precipitation characteristics already when increasing grid resolution from 50 to $10 \mathrm{~km}$ (Prein et al. 2016a). Simulations with a grid spacing of about $10 \mathrm{~km}$, however, still require the parametrization of deep convection, which is considered as a major source for model errors and uncertainty, like shifted summer-time diurnal cycles and an underestimation of intensity, frequency and spatial distribution of 
sub-daily precipitation (Brockhaus et al. 2008; Hohenegger et al. 2008; Hanel and Buishand 2010; Dirmeyer et al. 2012). Convection-permitting models require grid sizes below $4 \mathrm{~km}$ to simulate deep convection without the need for a parameterization scheme (Prein et al. 2015).

Convection-permitting models are commonly used in regional weather prediction since almost two decades because they exhibit more realistic precipitation patterns especially for convective events and over complex topography (Grell et al. 2000; Mass et al. 2002; Richard et al. 2007) and even for synoptic systems like low pressure systems and fronts (Leutwyler et al. 2016). In regional climate modeling however, convection-permitting simulations are rare because of their high computational costs and have so far been limited to small domain sizes (Knote and Heinemann 2010; Kendon et al. 2012; Prein et al. 2013; Fosser et al. 2015; Brisson et al. 2016) and/or seasonal simulations (Hohenegger et al. 2008; Langhans et al. 2013; Prein et al. 2013); simulations over Europe exceeding decadal time slices exist only for the southern British Isles (Kendon et al. 2012), the Alps (Ban et al. 2014), southwestern Germany (Fosser et al. 2015) and Belgium (Brisson et al. 2016). These limited simulations yield already significant improvements in sub-daily precipitation statistics, representation of extreme precipitation events, summer diurnal cycles of convective precipitation, and spatial structure of precipitation. A review paper on convection-permitting climate modeling by Prein et al. (2015) concludes, that the largest improvements are found for situations with dominant convective precipitation and over regions with heterogeneous land surface and complex topography.

With higher air temperatures, precipitation events are expected to intensify by $\sim 7 \% \mathrm{~K}^{-1}$ according to the Clausius-Clapeyron $(\mathrm{C}-\mathrm{C})$ relation for saturation water vapour pressure (Trenberth et al. 2003). Observation based studies suggest that the increase of hourly precipitation extremes with temperature can exceed $\mathrm{C}-\mathrm{C}$ scaling rates for daily mean temperatures above $12{ }^{\circ} \mathrm{C}$. This exceedance is most probably related to the release of latent heat in convective precipitation and in updrafts and the accompanied enhanced moisture convergence (Lenderink and van Meijgaard 2008; Berg et al. 2013; Lenderink et al. 2017). Globally, extreme precipitation scaling rates with temperature differ between regions (Utsumi et al. 2011; Wang et al. 2017). For very high temperatures, the extreme precipitation intensity starts to decrease with temperature increase when moisture supply becomes limited (Hardwick Jones et al. 2010; Chan et al. 2016). The temperature with the highest precipitation intensities and the subsequent negative scaling rate of precipitation with temperature depend on local climate conditions, i.e., especially moisture availability (Utsumi et al. 2011; Drobinski et al. 2016; Prein et al. 2016b; Wang et al. 2017).
Many global and regional climate model simulations with grid resolutions down to $10 \mathrm{~km}$, for example the EURO-CORDEX ensemble (Jacob et al. 2013) suggest an increase in daily extreme precipitation events with increasing temperature. So far, only few convection-permitting decade-long climate change mid or end-of-the-century simulations driven by GCM scenarios exist for European sub-domains (Kendon et al. 2014; Ban et al. 2015). Both Kendon et al. (2014) and Ban et al. (2015) found a decrease in future mean summer precipitation while subdaily heavy precipitation substantially increases. Scaled by the mean temperature change, these increases exceed the $\mathrm{C}-\mathrm{C}$ scaling rate in the UK (Kendon et al. 2014) but are consistent with the $\mathrm{C}-\mathrm{C}$ relation over the Alps (Ban et al. 2015). Interestingly, the observed larger than $C-C$ scaling in present-day climate is also replicated by the model in (Ban et al. 2014).

(Prein et al. 2016b) propose a general framework for the control mechanisms of temperature-precipitation scaling. In a long-term convection-permitting simulation for the Contiguous United States with a pseudo global warming approach, they show that observed and modeled scaling rates-both larger or smaller than the $7 \% \mathrm{~K}^{-1} \mathrm{C}-\mathrm{C}$ scaling-in different regions do not necessarily lead to an equally strong intensification of hourly precipitation extremes in a warmer future climate. Instead, the whole region-specific scaling curves are shifted to moister and warmer conditions according to the $\mathrm{C}-\mathrm{C}$ relation.

We present one of the first sets of decade-long convection-permitting regional climate simulations with the WRF RCM over Central Europe $(1440 \times 1368$ km) (Fig. 1). The simulations are carried out both for ERA-Interim reanalysis driven evaluation time slices and climate change projections for mid (MOC) and end-of-the-century (EOC) driven by a GCM RCP4.5 scenario simulation. We analyze sub-daily precipitation statistics and temperature-precipitation scaling both for convection-permitting and coarser resolution simulations with parameterized convection. To our knowledge, there is no study so far, that has done such a combined and comprehensive evaluation and analysis of current climate and projected RCP4.5 scenario simulations for different European sub-regions.

In Sect. 2, we introduce the WRF RCM simulations setup, observational data, and analysis methods. In Sect. 3, ERA-Interim reanalysis-driven evaluation simulations are compared against observations with a focus on the diurnal cycle, the intensity distribution of hourly precipitation, and the temperature-precipitation scaling. Section 4 investigates the convection-permitting future scenario runs with respect to the relative change in precipitation statistics in MOC and EOC simulations and its relation to the mean temperature change. 
Fig. 1 Central European model domain (3 km grid size) nested into EURO-CORDEX domain (12 km grid size, EUR-11) as shown in small map upper left. Dots show rain gauge stations for different altitude ranges (blue: $<400 \mathrm{~m}$, green: 400 $900 \mathrm{~m}$, red: $>900 \mathrm{~m})$. Colored boxes indicate different analysis regions (blue: Lowlands, green: Uplands, red: Alpine, yellow: Northern Italy, pink: Southern France)

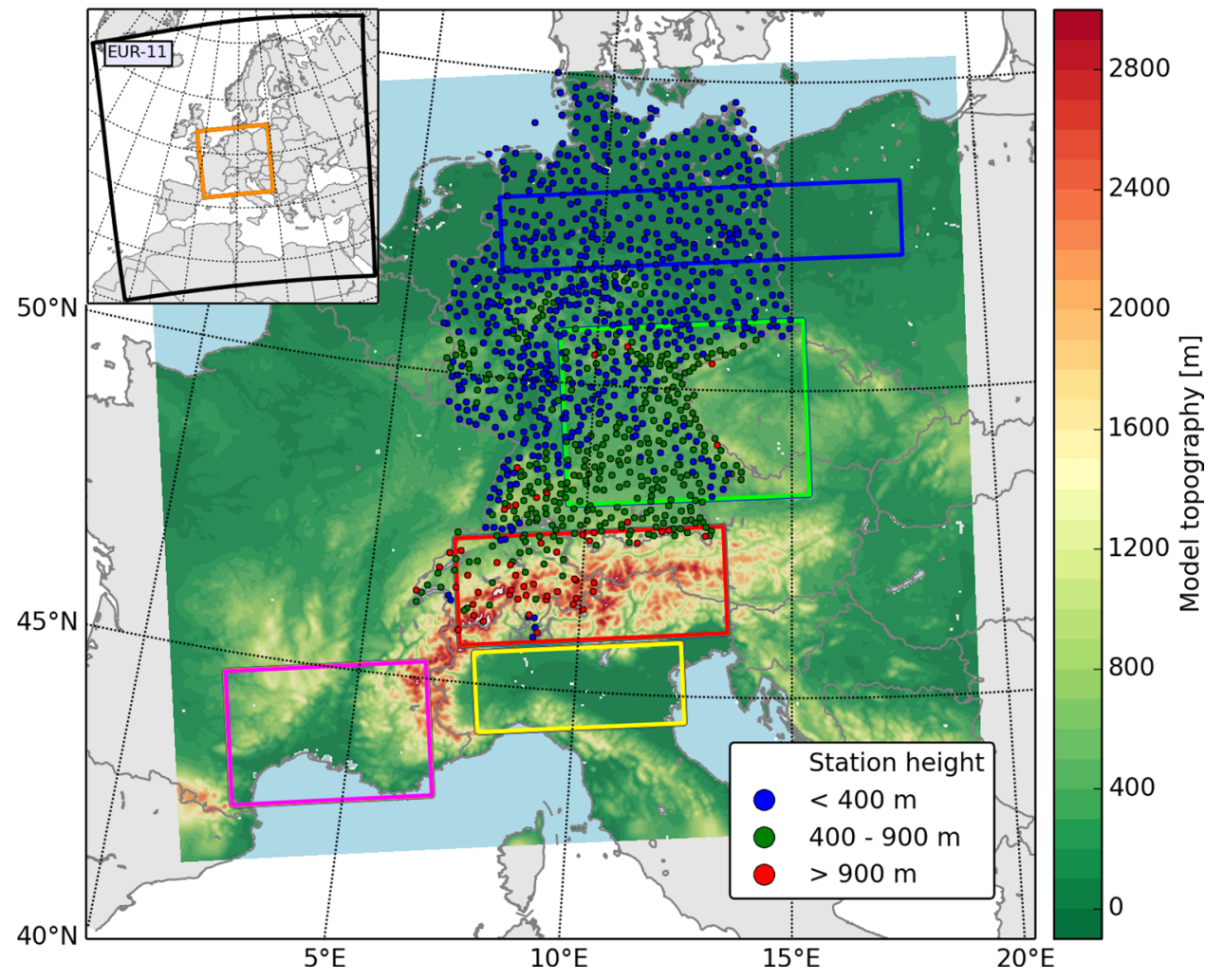

\section{Data and methods}

\subsection{RCM simulations}

We perform regional climate simulations for Central Europe with the non-hydrostatic Weather Research and Forecasting model (WRF/ARW, v3.6.1) (Skamarock et al. 2008) in a one-way double nesting setup (Fig. 1). The model domain is resolved with a $0.0275^{\circ}(\sim 3 \mathrm{~km})$ grid spacing $(480 \times 456$ grid points), nested into the pan-European $0.11^{\circ}(\sim 12 \mathrm{~km})$ Euro-CORDEX domain (EUR-11,448 $\times 436$ grid points), both with 50 vertical levels up to $20 \mathrm{hPa}$. The $12 \mathrm{~km}$ simulation uses the Grell-Freitas convection scheme (Grell and Dévényi 2002) that is switched off in the $3 \mathrm{~km}$ domain. All other model configurations and parameterizations are the same for the $3 \mathrm{~km}$ and the $12 \mathrm{~km}$ simulation to avoid differences between both that might result from another parameterization. Both use WSM-5 microphysics (Hong et al. 2004), RRTMG radiation (Iacono et al. 2008), the YSU PBL scheme (Hong et al. 2006) and the NOAH land surface model (Ek et al. 2003). This choice of setup results from several validation studies of WRF Euro-CORDEX evaluation simulations (Kotlarski et al. 2014; García-Díez et al. 2015; Katragkou et al. 2014). Since the $3 \mathrm{~km}$ domain is directly nested into the EUR-11 domain, both simulation types share the same boundary conditions for Central Europe. Output is written in hourly time steps to largely resolve short-term extreme precipitation.
Two experiments have been conducted, both using the same model configuration as described above. First, evaluation climate simulations were carried out for the three time slices 1993-1995, 2002-2003, 2010-2013, which are chosen to cover most of the climate variability in Central Europe including both wet and dry as well as cold and hot years like, e.g., the wet winter of 1994, the wet summer of 2002 , and the particularly dry and hot summer of 2003. Sixhourly ERA-Interim reanalysis data $\left(0.75^{\circ}\right.$ grid, 60 levels $)$ (Dee et al. 2011) provide the lateral boundary data for the EUR-11 domain and the sea surface temperatures for both domains. Each time slice starts in November of the previous year with a 2 months spinup. Initial soil moisture, soil temperature and snow are taken from a former 20 year EUR11 simulation with a similar setup as used in Knist et al. (2017). The second experiment consists of three 12.5 year simulations, which downscale global climate model runs of the Earth System Model of the Max-Planck-Institute (MPI-ESM-LR r1i1p1) (Stevens et al. 2013) for a control period (CTRL; 1993-2005) and for the future mid-century (MOC; 2038-2050) and end-of-century (EOC; 2088-2100) using an Representative Concentration Pathways version 4.5 (RCP4.5) greenhouse gas scenario.

\subsection{Observations}

Two national hourly station datasets (Fig. 1) are used for the evaluation of the ERA-Interim driven simulations at 12 
and $3 \mathrm{~km}$ resolution: 1014 rain gauge stations over Germany provided by the Deutscher Wetterdienst (DWD, ftp:// ftp-cdc.dwd.de/pub/CDC/observations_ germany/climate/ hourly/precipitation/historical, last access: 12 July 2017) and 80 stations over Switzerland from the MeteoSwiss ANETZ (automatic monitoring network, (https://gate.meteoswiss .ch/idaweb/login.do, last access: 12 July 2017). All Swiss stations cover the complete evaluation time span and about $80 \%$ of the German stations provide data for at least 7 years. Temperature observations are collected for all Swiss stations and 594 of the German stations.

\subsection{Methods}

We focus our analysis on mean diurnal cycles and intensity distributions of hourly precipitation sums. For the model to observation comparison, RCM data is extracted from the grid point closest to each observation station. For the comparison of $3 \mathrm{~km}$ (WRF3) and $12 \mathrm{~km}$ (WRF12) model data, the WRF3 fields are averaged to the WRF12 fields via conservative remapping (Jones 1999) resulting in WRF3_12 fields that conserve the integral of precipitation over the domain.

Metrics are computed for all grid points, for which at least one station is available and then averaged over all stations as well as selected altitude ranges (see Fig. 1 for the station distribution). For the intensity distributions (Fig. 3), spatial averaging results from pooling of all stations and respective grid points that belong to a certain altitude range. Precipitation percentiles are calculated based on all hours, including dry hours; thus when comparing percentiles, these are not affected by different numbers of wet hours in the different model simulations and observations. This approach follows a recommendation by Schär et al. (2016) and differs from other studies assessing heavy precipitation characteristics that use percentiles calculated only based on wet hours (e.g., defined as hours with precipitation sum $>0.1 \mathrm{~mm}$ ); with this approach percentiles cannot be directly compared between different studies or different model simulations and may lead to misleading conclusions if the percentage of the wet hours changes (Schär et al. 2016).

We focus our analysis on the scaling of extreme precipitation with temperature and compare the scaling with the Clausius-Clapeyron scaling which predicts $\sim 7 \% \mathrm{~K}^{-1}$. C-C scaling assumes that in a warming climate extreme precipitation will further increase with the same rate (Allen and Ingram 2002; Trenberth et al. 2003). We calculate the scaling from daily mean $2 \mathrm{~m}$ air temperatures and the daily maximum hourly precipitation following the method first applied by (Lenderink and van Meijgaard 2008): for each station or model grid, daily maximum hourly precipitation over the investigated period is attributed to the daily mean temperature over the same period sorted into $1{ }^{\circ} \mathrm{C}$ bins. To account for different station and grid surface altitudes, temperature is extrapolated to sea level by assuming a lapse rate of $0.0065 \mathrm{Km}^{-1}$. For each temperature bin with more than 100 samples, the 99 th percentile of the precipitation values $\left(\mathrm{P} 99_{\mathrm{dmax}}\right)$ is calculated. The $\mathrm{P} 99_{\mathrm{dmax}}$ values are then averaged over the stations or grid points in the particular analysis region.

The significance of differences in mean precipitation and intensities above the 99.9th percentile between stations and simulations are estimated with the Mann-Whitney-Wilcoxon test. For changes in mean precipitation significance is tested with respect to inter-annual variability at a significance level of 0.05 .

\section{Validation and added value of convection-permitting simulations}

\subsection{Mean diurnal cycle of precipitation}

Daytime land surface heating during summer leads to a diurnal cycle in convective processes and the ensuing evolution of clouds and precipitation. We compare the mean diurnal precipitation cycles in summer (JJA) in both 12 and $3 \mathrm{~km}$ WRF simulations with the station data over Germany and Switzerland (Fig. 2). The results for the $3 \mathrm{~km}$ simulation, both the original $3 \mathrm{~km}$ grid data (WRF3, yellow) and their $12 \mathrm{~km}$ averages (WRF3_12, red) differ only marginally for all stations (Fig. 2a) and also for the individual altitude ranges (Fig. 2b-d). Clear differences are obvious between coarse and high-resolution runs and the observations. The amplitude of the diurnal cycles from the WRF simulations is larger and shifted to earlier times by about 3 (WRF3) and 4 (WRF12) hours compared to the observations, which peak at 18 UTC. While the nighttime precipitation amount in WRF12 better matches the observations (WRF3 clearly underestimates), the amplitudes and phasing during daytime are better simulated by WRF3, except for the low altitude stations (Fig. 2b). Overall, WRF12 results in larger mean precipitation than WRF3, and both overestimate average precipitation, except in the lowlands (Fig. 2b).

Results slightly differ for regions at different altitudes (compare Fig. 2b-d). The height ranges $<400 \mathrm{~m}$ are mainly located in northern Germany, 400-900 $\mathrm{m}$ in the central and southern German Uplands, and $>900 \mathrm{~m}$ in the Alpine region (see Fig. 1 for the station locations). For stations $<400 \mathrm{~m}$ the phases of the diurnal cycles from WRF3_12 and WRF3 are quite similar with WRF12, showing roughly 10-20\% more precipitation than WRF3; both underestimate nighttime precipitation compared to stations. While the timing of the precipitation peak is delayed by about $3 \mathrm{~h}$ in both simulations, the daily maximum precipitation differs by only $5 \%$ from the observations. For upland stations (Fig. 2c, d) 

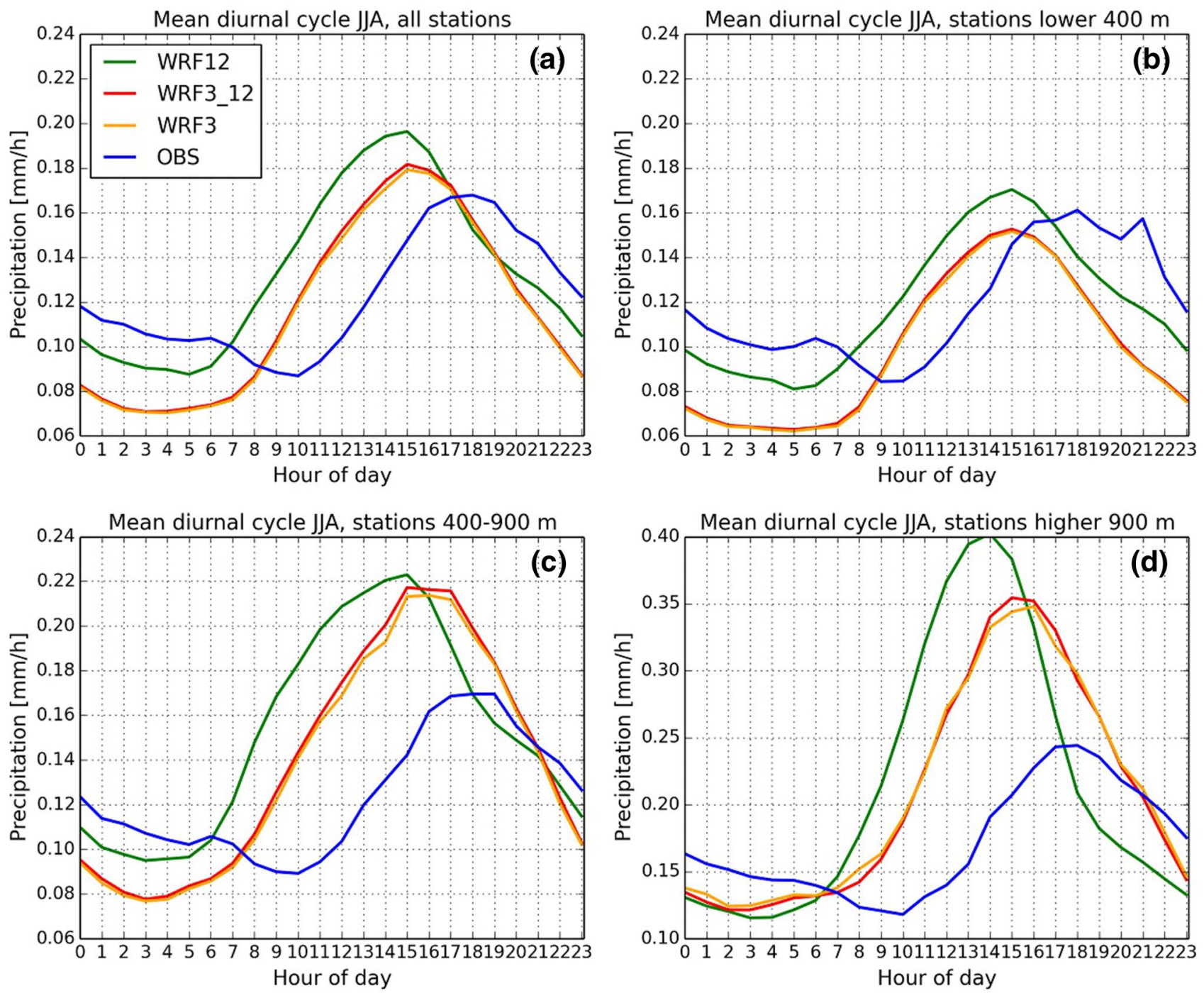

Fig. 2 Mean diurnal cycle of summer (JJA) precipitation based on all rain gauge stations (blue lines) (a), lowland stations $(<400 \mathrm{~m})(\mathbf{b})$, uplands stations (400-900 m) (c) and Alpine stations (>900 m) (d). Green lines indicate the ERA-Interim driven $12 \mathrm{~km}$ WRF simulation

(WRF12), yellow lines the $3 \mathrm{~km}$ simulation (WRF3) and red lines the $3 \mathrm{~km}$ results interpolated on $12 \mathrm{~km}$ grid (WRF3_12). For each station the nearest model grid point is taken into account

there is a phase shift of $1-2 \mathrm{~h}$ between both simulations with WRF3 being closer to the observations. Both simulations clearly overestimate amplitude and mean daytime precipitation, especially for the Alpine region. While nighttime precipitation amounts are similar, a much too large maximum of $0.40 \mathrm{~mm} / \mathrm{h}$ is reached already at $14 \mathrm{UTC}$ by WRF12 compared to $0.35 \mathrm{~mm} / \mathrm{h}$ at $15 \mathrm{UTC}$ in WRF3 and $0.25 \mathrm{~mm} / \mathrm{h}$ at 17 UTC in the observations.

Overall, both the timing and amount of peak precipitation are slightly better reproduced by the convection-permitting WRF3 simulation. But compared to studies by Kendon et al. (2012) and Ban et al. (2014), the improvement by the higher resolution runs is less pronounced. This is, however, in agreement with Prein et al. (2013), who found

that the improvement of precipitation diurnal cycle by convection-permitting models over coarser-scale runs are model-dependent with WRF simulations showing the smallest differences.

\subsection{Hourly precipitation intensity}

During winter time (DJF, dashed lines, Fig. 3a) low and medium hourly precipitation intensities have similar occurrences between WRF12 and WRF3/WRF3_12 but are more frequent compared to the observations; accordingly, the occurrence of heavy precipitation ( $>6 \mathrm{~mm} / \mathrm{h}, \mathrm{P} 99.99)$ is underestimated especially by WRF12 (Fig. 3a). Differences between both resolutions are larger during the summer 

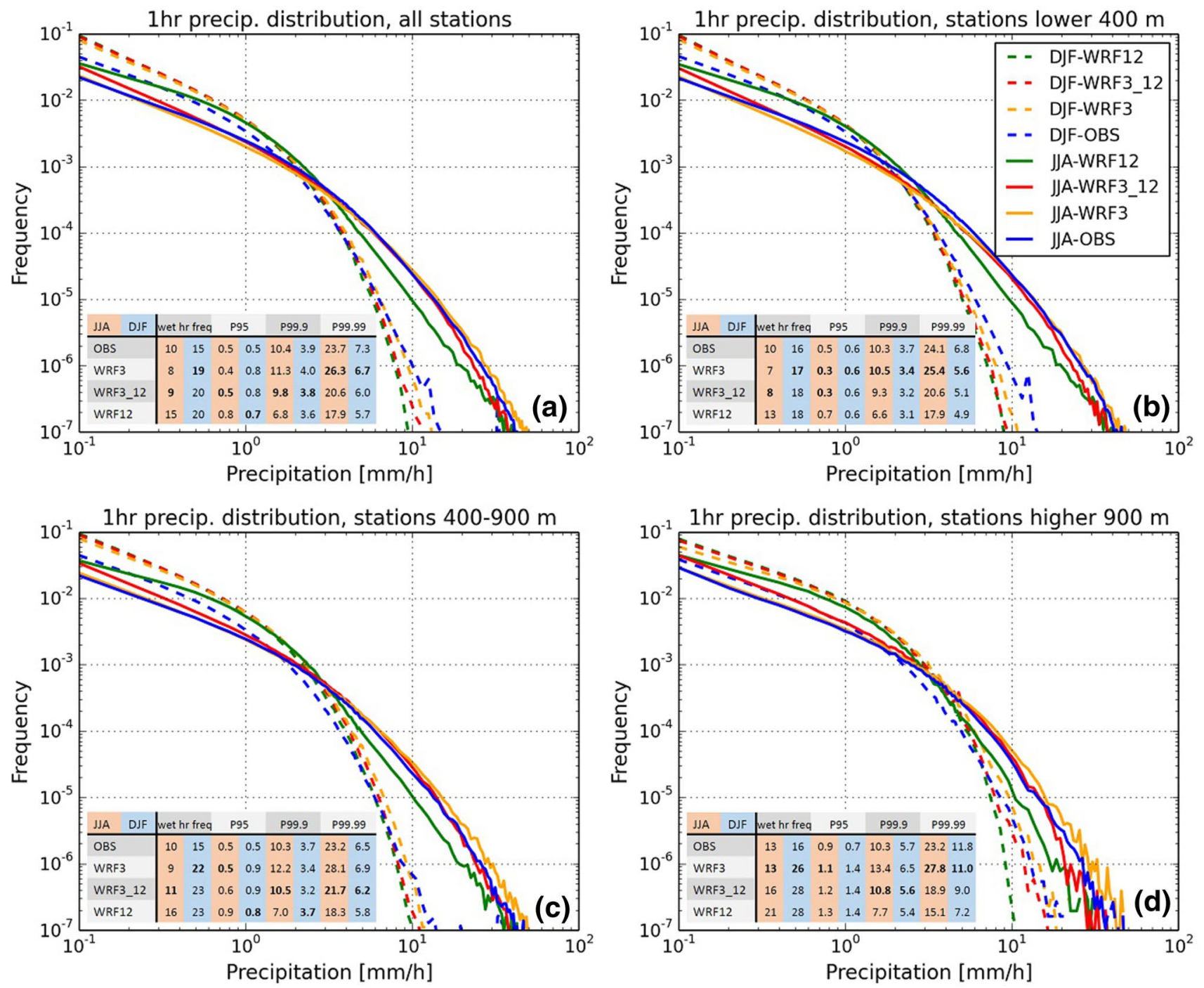

Fig. 3 Intensity distribution of hourly precipitation based on all rain gauge stations (blue lines) (a), lowland stations $(<400 \mathrm{~m})(\mathbf{b})$, uplands stations (400-900 m) (c) and Alpine stations (>900 m) (d). Green lines indicate the ERA-Interim driven $12 \mathrm{~km}$ WRF simulation (WRF12), yellow lines the $3 \mathrm{~km}$ simulation (WRF3) and red lines the $3 \mathrm{~km}$ results interpolated on $12 \mathrm{~km}$ grid (WRF3_12). For each station

months (JJA, solid lines, Fig. 3a). The larger precipitation amounts by WRF12 are produced by a much higher occurrence of light and medium precipitation, which overcompensates the underestimated occurrence of heavy and extreme precipitation. Overall, WRF3/WRF3_12 results better fit the observations as also indicated by the percentage of wet hours and the 95th, 99.9th and 99.99th percentiles of hourly precipitation including dry hours (see tables in Fig. 3). For very high hourly precipitation sums $(>10 \mathrm{~mm} / \mathrm{h}) \mathrm{WRF} 3$ data even slightly exceeds the observations. As model data represent spatial averages over the grid box area, extreme values that are found in point observations may be smoothed even at the high $3 \mathrm{~km}$ resolution.

the nearest model grid point is taken into account. Solid lines show results for summer (JJA), dashed lines for winter (DJF). Tables show the wet hour frequency in \% and 95th, 99.9th and 99.99th hourly precipitation percentiles in $\mathrm{mm}$, whereby bold printed values are closest to the observation

Similar behavior is seen for all height ranges (Fig. 3b-d): overestimation of light and moderate precipitation in WRF12 in summer and in both simulations in winter, underestimation of heavy precipitation in WRF12, overall much better reproduction of heavy precipitation in WRF3_12 and WRF3, especially in summer. In winter, when convection is less frequent, the largest difference between both resolutions occurs for the Alpine region, where heavy precipitation events are better represented in WRF3 most likely due to the better resolved orography. In summer, heavy precipitation in mountainous regions is slightly overestimated as also reported in previous studies in this region (Langhans et al. 2013; Prein et al. 2013; Ban et al. 2014). The overall better 
reproduction of hourly precipitation intensity distributions confirms findings in other convection permitting climate simulations (Kendon et al. 2012; Ban et al. 2014; Fosser et al. 2015; Brisson et al. 2016).

\subsection{Temperature-extreme precipitation scaling}

We compare in Fig. 4 the simulated and observed temperature-extreme precipitation scaling rates by plotting the 99th percentile of the daily maximum hourly precipitation $\left(\mathrm{P} 99_{\mathrm{dmax}}\right)$ as a function of daily mean temperature
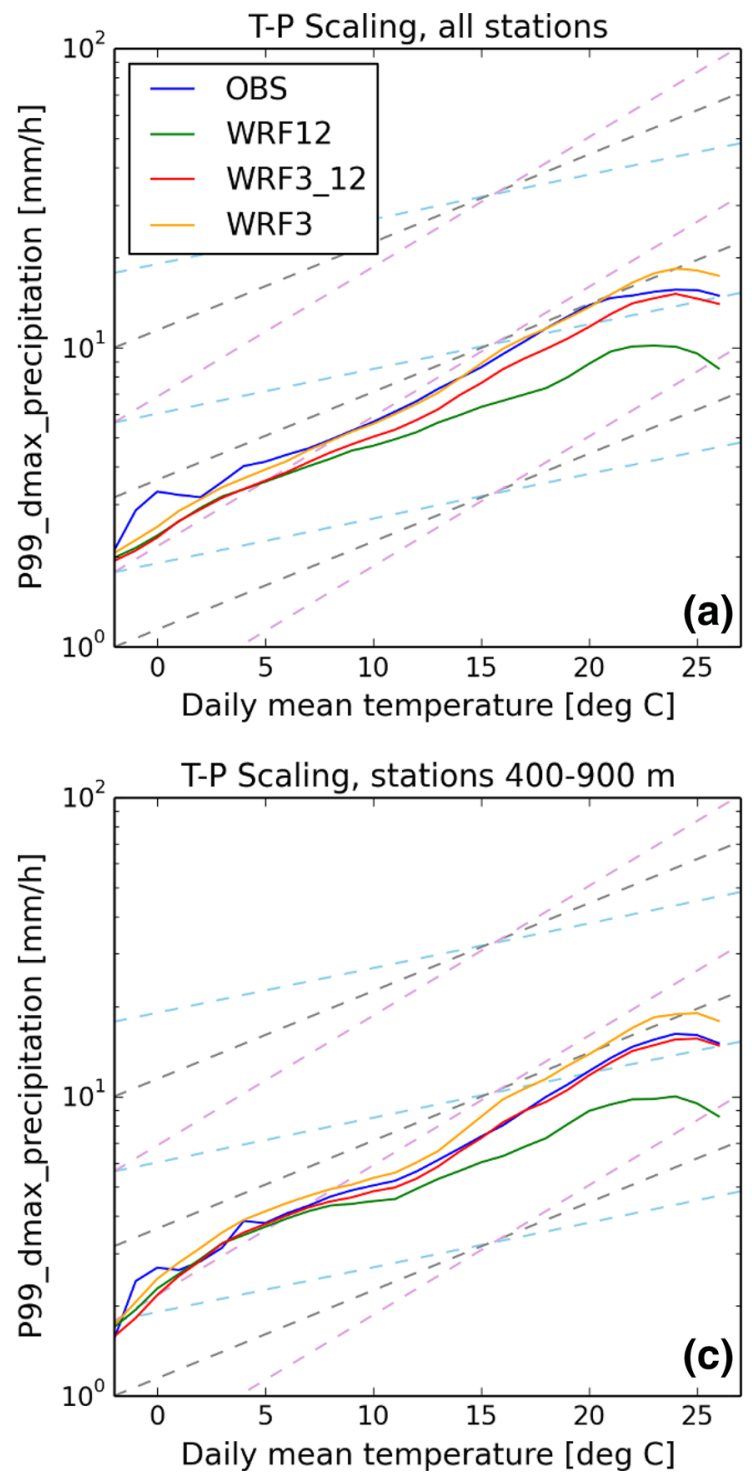

Fig. 4 Temperature-extreme precipitation scaling in the ERAInterim driven WRF12 (green), WRF3_12 (red) and WRF3 (yellow) compared to station observations (blue) based on all stations (a), on lowland stations $(<400 \mathrm{~m})(\mathbf{b})$, on uplands stations $(400-900 \mathrm{~m})(\mathbf{c})$ and lower right on Alpine stations (>900 m) (d). For each grid point nearest to a station daily maximum hourly precipitation is discretized into one-degree bins of daily mean temperature. To account for dif- extrapolated to mean sea level for all stations (Fig. 4a) and separated for different altitude ranges (Fig. 4b-d). Overall, both model simulations agree with the observations in the $\mathrm{C}-\mathrm{C}$ scaling of $7 \% \mathrm{~K}^{-1}$ (indicated by the gray dashed lines) for the temperature range from 0 to $11^{\circ} \mathrm{C}$. From 11 to $22^{\circ} \mathrm{C}$ WRF3 and WRF3_12 follow the stronger (super-adiabatic) T-P99 scaling $\left(\sim 10 \% \mathrm{~K}^{-1}\right)$ of the observations, which is not reproduced by WRF12. This finding is consistent with the differences found in the precipitation intensity distributions between both resolutions and observations in summer compared to winter (Fig. 3).
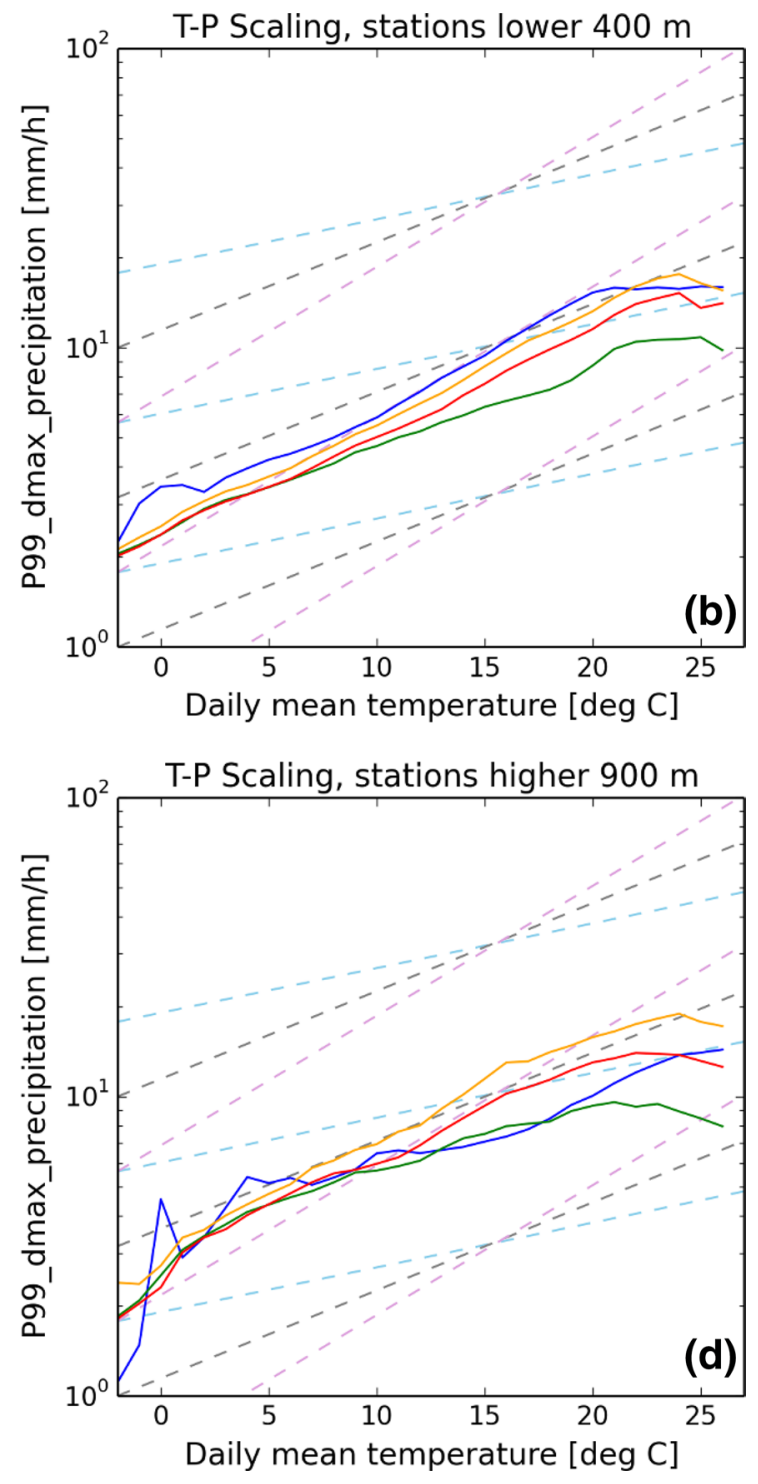

ferent altitudes, temperature is extrapolated to sea level by assuming a lapse rate of $0.0065 \mathrm{Km}^{-1}$ first. For each temperature bin with a sample size larger than 50 the 99 th percentile of the precipitation values $\left(\mathrm{P} 99_{\mathrm{dmax}}\right)$ is calculated and averaged over all stations. Light blue, grey and pink dashed lines indicate a scaling of $3.5,7$ and $10.5 \% \mathrm{~K}^{-1}$ (according $0.5,1$ and 1.5 times $\mathrm{C}-\mathrm{C}$ scaling rate), respectively 
For temperatures above $22{ }^{\circ} \mathrm{C}$, the scaling flattens or even reverses to lower $\mathrm{P} 99_{\mathrm{dmax}}$ values in both simulations and observations, indicating the transition to a dry regime where high temperatures are accompanied with limited moisture supply as it is shown in a similar study by Prein et al. (2016a, b). For even higher temperatures, the relation becomes uncertain due to the low number of occurrences.

The scaling curves for WRF3 have a similar shape as WRF3_12 but are shifted to overall slightly higher precipitation. Overall, the scaling rates are slightly stronger in WRF3 $(+0.2 \% / \mathrm{K})$. However, this effect of regridding from WRF3 to WRF3_12 is relatively small compared to the difference between WRF3_12 to WRF12. In line with the intensity distributions (Fig. 3), the scaling curves of WRF3 are closest to the observations for lowland stations, but slightly overestimate the extreme precipitation for uplands (400-900 m) and Alpine stations (>900 m). WRF3_12 fits the observed super-adiabatic scaling rates for temperatures above $12{ }^{\circ} \mathrm{C}$ best for the uplands stations. For lowlands stations, the simulated P99 ${ }_{\text {dmax }}$ values are somewhat lower than in the observations. For the Alpine region, scaling curves from simulations and observations are less homogeneous and scaling rates are overall slightly weaker than for lowlands and uplands. Besides topography related effects, like forced ascending and differential heating at mountain slopes, also artefacts due to the-now much larger-extrapolation of temperature to mean sea level may play a role. Overall, however, our results are in

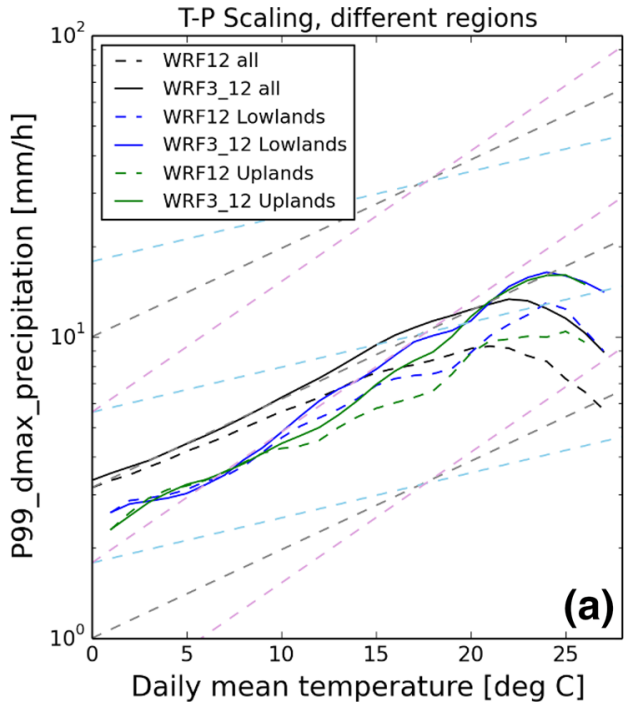

Fig. 5 Temperature-extreme precipitation scaling in the ERA-Interim driven WRF12 (dashed) and WRF3_12 (solid) for different analysis regions. a all domain grid points (black), lowlands (blue), uplands (green); b alpine (red), southern France (yellow) and northern Italy (purple), see Fig. 1 for the definition of the analysis regions. For each grid point in a region daily maximum hourly precipitation is discretized into one-degree bins of daily mean temperature with $1^{\circ}$ overlap. line with e.g. Lenderink and van Meijgaard (2008) and Ban et al. (2014).

We extend now the comparison on the temperature-extreme precipitation scaling (T-P99 ${ }_{\text {dmax }}$ ) between the 12 and $3 \mathrm{~km}$ simulations to the whole model area to extend the range of climate conditions, albeit at the expense of missing observations (Fig. 5). Thus, spatial averages over all grid points are compared without the restriction of available observations. The scaling curves for the Lowland and Upland regions (blue and green curves in Fig. 5a) largely resemble the respective curves shown in Fig. 4 since most of the stations are located in these areas. Both show $\mathrm{C}-\mathrm{C}$ scaling in the temperature range from 0 to $10{ }^{\circ} \mathrm{C}$, increasing to super-adiabatic scaling in WRF3_12 for $10-22{ }^{\circ} \mathrm{C}$ and a drop for higher temperatures. In southern France and northern Italy (pink and yellow curves in Fig. 5b) the drop of P99 dmax $_{\text {a }}$ already starts at about $17^{\circ} \mathrm{C}$, which is most probably related to dry and hot summer conditions combined with insufficient precipitable water to generate strong precipitation (Prein et al. 2016b). The convection-permitting runs (WRF3_12, solid lines) generate overall higher P99 ${ }_{\text {dmax }}$ values in all analysis regions than the coarse resolution runs (WRF12, dashed lines). Differences are small from 0 to $10^{\circ} \mathrm{C}$, but WRF12 is completely missing the increase in scaling rate for higher temperatures. While higher precipitation values can be expected for regions with steep orography, like the Alps, the higher P99 ${ }_{\mathrm{dmax}}$ values for the same temperatures in southern France and northern Italy compared to the other

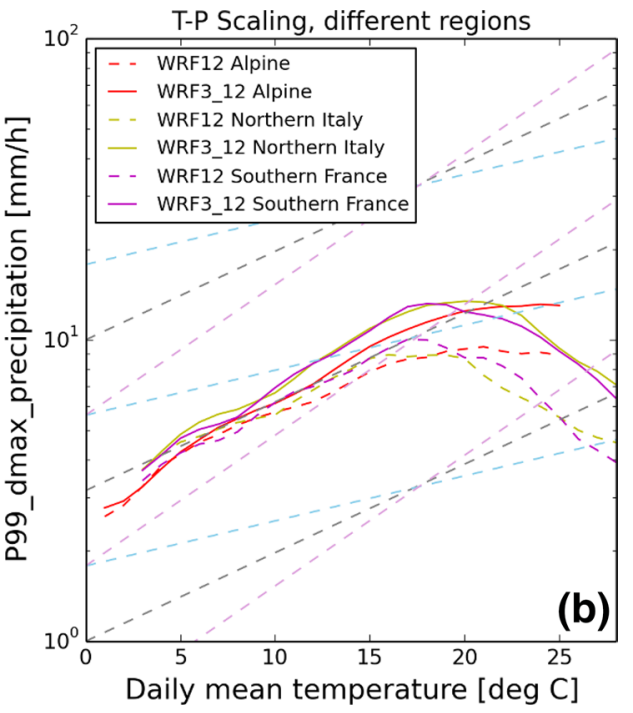

To account for different altitudes, temperature is extrapolated to sea level by assuming a lapse rate of $0.0065 \mathrm{Km}^{-1}$ first. For each temperature bin with a sample size larger than 100 the 99 th percentile of the precipitation values ( $\left(\mathrm{P} 99_{\mathrm{dmax}}\right)$ is calculated and averaged over all grid points. Light blue, grey and pink dashed lines indicate a scaling of $3.5,7$ and $10.5 \% \mathrm{~K}^{-1}$ (according $0.5,1$ and 1.5 times $\mathrm{C}-\mathrm{C}$ scaling rate), respectively 
regions must result from other local (thermo-)dynamic conditions (local wind systems, advection of moist air masses from the Mediterranean Sea, atmospheric stability).

The regionally different scaling curves result in a slightly flatter scaling rate for the whole domain average (black line, Fig. 5a), also largely masking the increase to a super-adiabatic scaling rate for warmer temperatures. Prein et al. (2016a, b) also found regionally different scaling curves over the USA and identified moisture as a limiting factor for extreme precipitation at high temperatures. For Central Europe the regional climate is less diverse, but the impact on the scaling curves is still detectable. The interpretation and comparison of scaling curves, averaged over regions with varying topography, has to be done with care. Averaging over different grid point or station heights without height corrections of the near-surface temperature and accordingly different near surface temperatures leads to flatter scaling curves.

\section{Climate change projection simulations}

We now investigate projected future precipitation statistics from downscaled MPI-ESM-LR GCM runs in a RCP4.5 scenario. Changes with respect to the control time period (CTRL) from 1993 to 2005 are analyzed for the mid-of-thecentury (MOC) period from 2038 to 2050 and the end-ofthe-century (EOC) period from 2088 to 2100 , both for the $3 \mathrm{~km}$ convection-permitting runs (WRF3_12) and its driving $12 \mathrm{~km}$ resolution (WRF12) simulation.

\subsection{Projected changes in mean and heavy precipitation}

On domain average, WRF12 generates more precipitation compared to WRF3_12 for the control period in summer (JJA) (Fig. 6, left subplots), mainly over lowland regions.
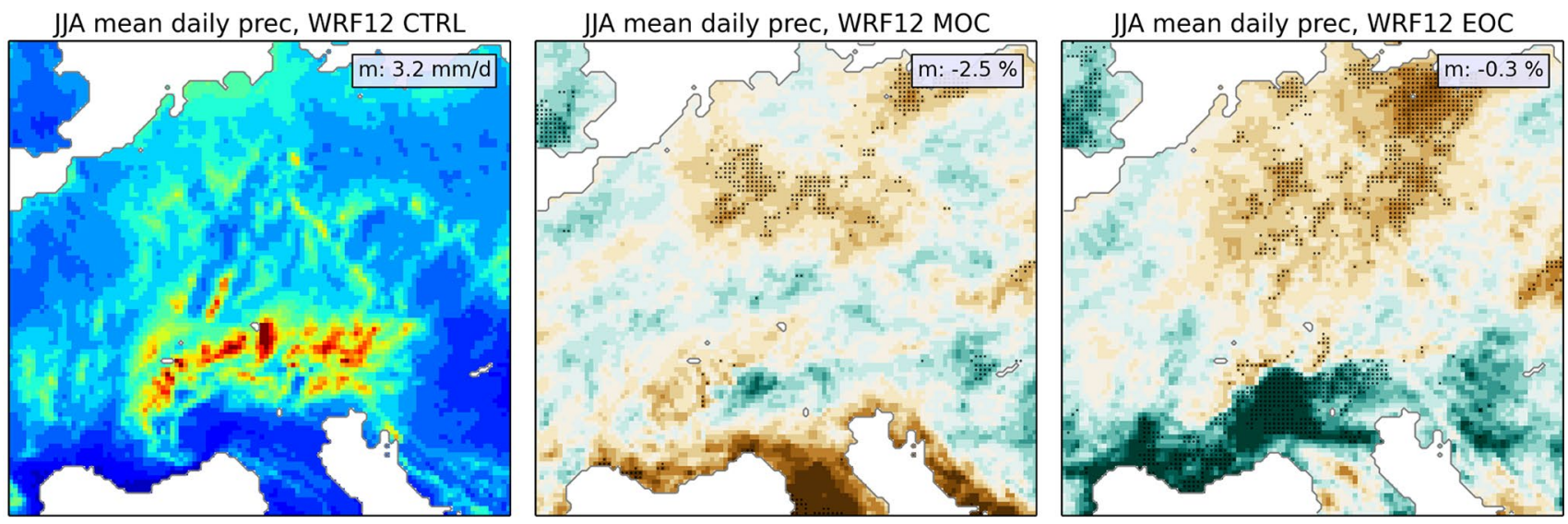

JJA mean daily prec, WRF3_12 CTRL
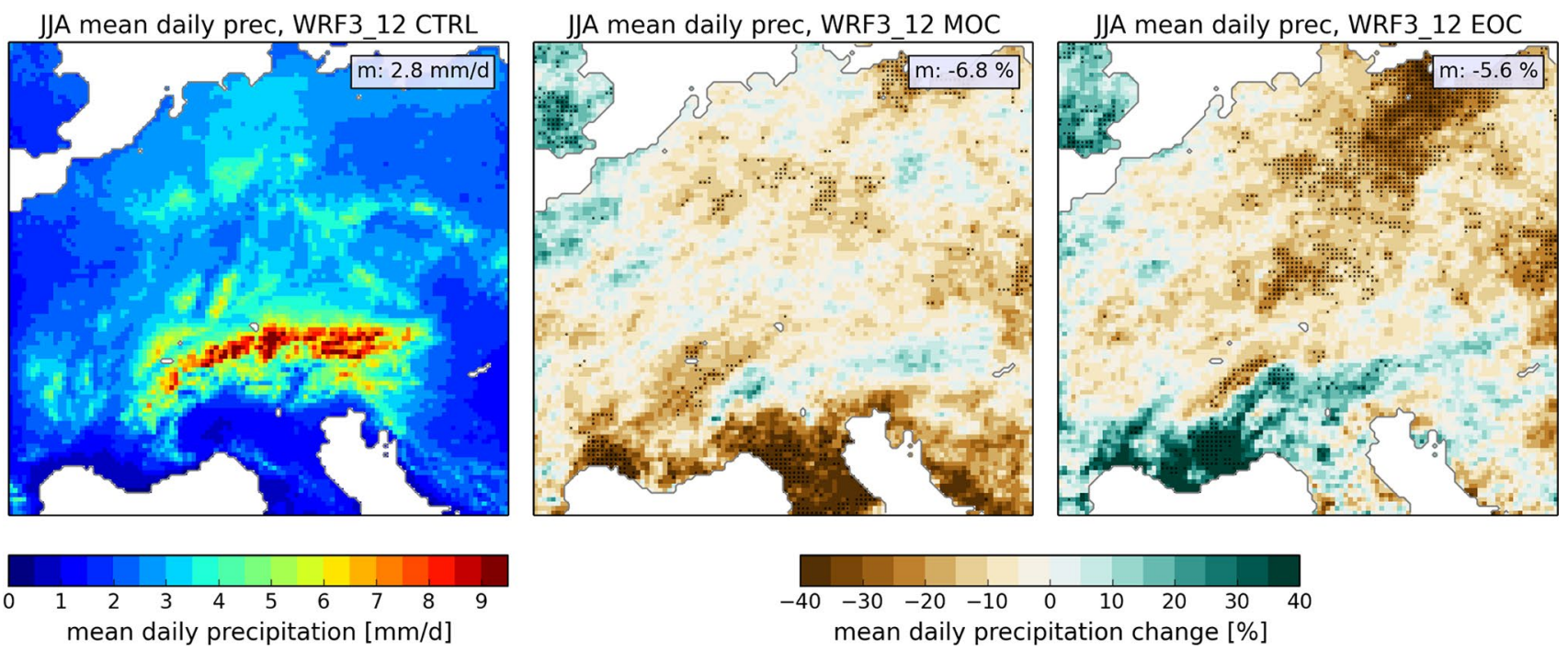

Fig. 6 Summer (JJA) mean precipitation $[\mathrm{mm} / \mathrm{d}]$ in the CTRL simulation time period (left) and its relative change in MOC (middle) and EOC (right) for WRF12 (upper row) and WRF3_12 (lower row).
Domain mean changes are indicated in the top right corner. Dots highlight significant changes ( 0.05 level) 
Both simulate reasonable spatial distributions with highest precipitation amounts over the uplands and Alpine mountain ranges, whereby precipitation is regionally higher in WRF3_12, and dry conditions in southern France and northern Italy. For the near and the far future, WRF12 and WRF3_12 largely agree in the predicted coarse scale precipitation change pattern (Fig. 6, middle and right subplots). Both simulate 15-40\% less precipitation for the Mediterranean region for MOC; the convection-permitting run in addition indicates overall less precipitation for Central Europe. For end-of-century (EOC) both simulations project $10-30 \%$ drier conditions over Germany and Poland but $15-40 \%$ more precipitation over southern France and northern Italy. However, changes are significant for only $21 \%$ of grid points given the range of the inter-annual variability. Prominent, however, is the much stronger and more wide-spread increase of projected precipitation south of the Alps in the WRF12 simulations. Please note that for regions with little precipitation small changes in absolute precipitation appear large in relative changes. The overall tendency to drier conditions is slightly stronger in WRF3_12; the domain-averaged difference of mean precipitation between WRF12 (wetter) and WRF3_12 (drier) increases from 16\% in CTRL to $20 \%$ in MOC and $22 \%$ in EOC.

Differences between WRF12 and WRF3_12 are generally smaller in winter (DJF, Fig. 7). Except for local differences in mountainous regions, the spatial distribution and the mean precipitation is similar, both for the CTRL time period and the projected changes. For MOC both simulate 10-20\% more precipitation for some parts of France and Germany, while drier conditions are projected for the eastern Alpine region and parts of Czech Republic. Relative changes are overall stronger for EOC with a $15-40 \%$ decrease in mean precipitation for the Mediterranean region and a 10-30\% increase for large parts of Central Europe north of the Alps. Again, for most grid points the changes are not significant.
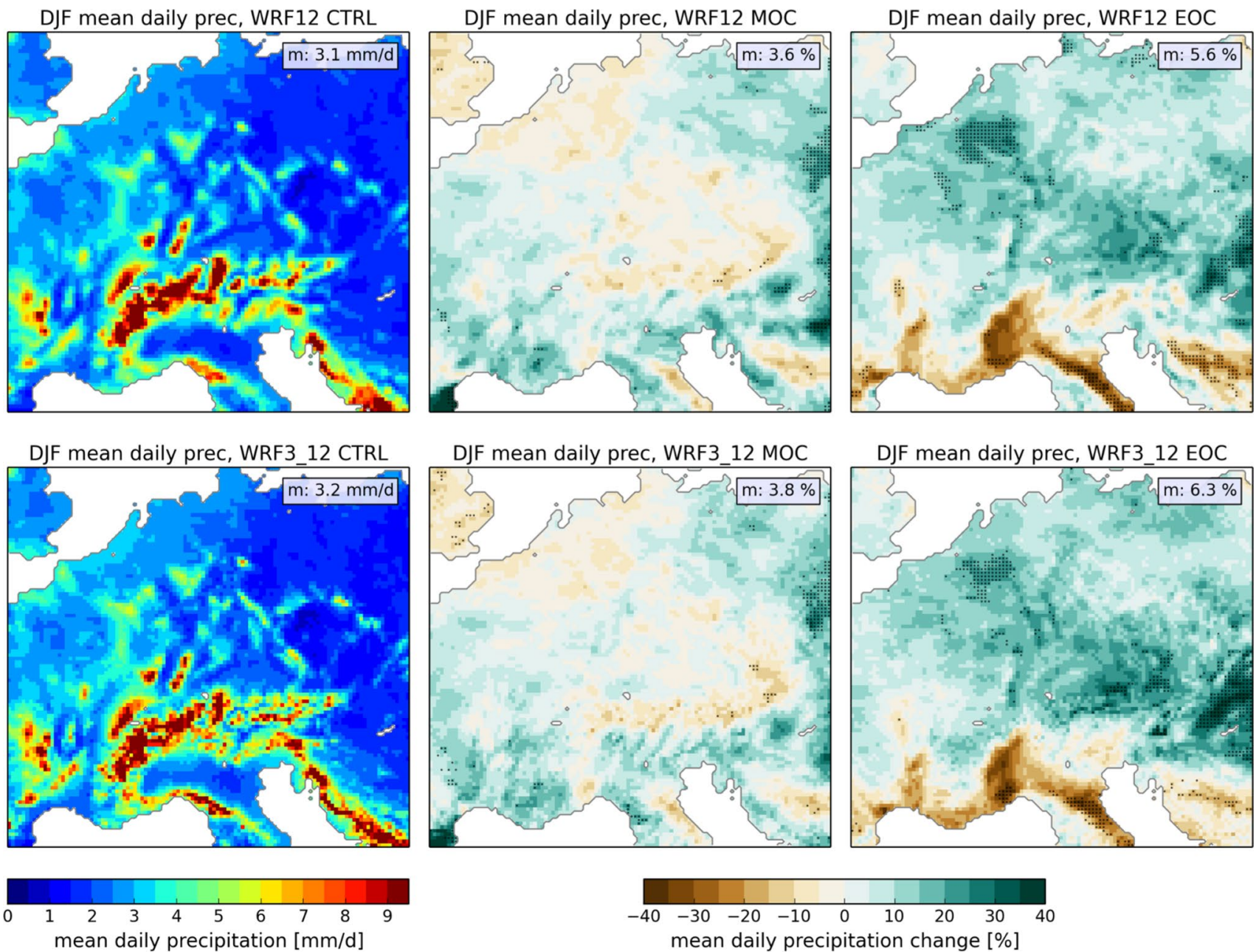

mean daily precipitation $[\mathrm{mm} / \mathrm{d}]$

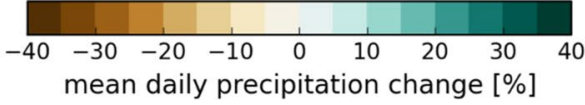

Fig. 7 Winter (DJF) mean precipitation $[\mathrm{mm} / \mathrm{d}]$ in the CTRL simulation time period (left) and its relative change in MOC (middle) and EOC (right) for WRF12 (upper row) and WRF3_12 (lower row).
Domain mean changes are indicated in the top right corner. Dots highlight significant changes (0.05 level) 
The large scale precipitation changes are similar to the driving GCM (not shown), especially the drier (wetter) pattern south (north) of the Alps in EOC winter and the drier Mediterranean region in summer. However, the large increase for summer precipitation in EOC in southern France and southern Alpine region is less prominent in the GCM simulation. This is most-probably related to a more southerly flow in the simulated decade, as the 30-year summer mean (2071-2100 vs. 1971-2000) indicates a precipitation decrease in whole Southern and Central Europe. The projected domain average precipitation decrease in summer is slightly larger in the GCM simulation that projects $-5 \%$ for MOC and $-10 \%$ for EOC. In winter, the projected little change in mean precipitation change is similar in the GCM and WRF simulations.

Summertime extreme precipitation (99.9th percentile) during the control period is considerably stronger in the convection-permitting simulations (Fig. 8, left sub-plots) in agreement with the validation results. Unlike for mean precipitation, both simulations indicate an increase in extreme precipitation for MOC $(+5 \%$ domain average in WRF3_12, +3\% in WRF12) and EOC (+12\% for WRF3_12, +8\% for WRF12). The noisy change pattern in MOC and EOC reflects the internal variability in these free running simulations, caused by these isolated and usually very local events. The regional stronger increase in southern France and southwestern UK is accompanied by an increase in mean precipitation in these areas (see Fig. 6).

In winter, WRF3_12 and WRF12 show a similar increase in P99.9 of 5\% on average for MOC and $10 \%$ for EOC (Fig. 9). The pattern is overall slightly more homogeneous compared to the summer months and also more consistent in both resolutions including significant increases of extreme precipitation especially in eastern Europe. In southern France and northern Italy, the decrease in EOC
JJA P99.9 1hr precip, WRF12 CTRL

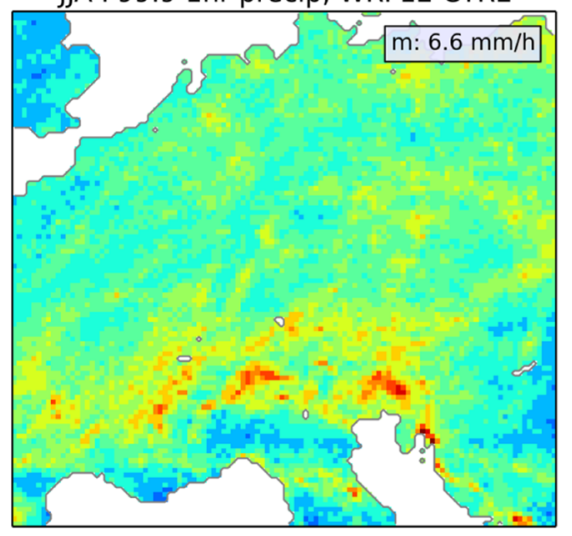

JJA P99.9 1hr precip, WRF3 12 CTRL
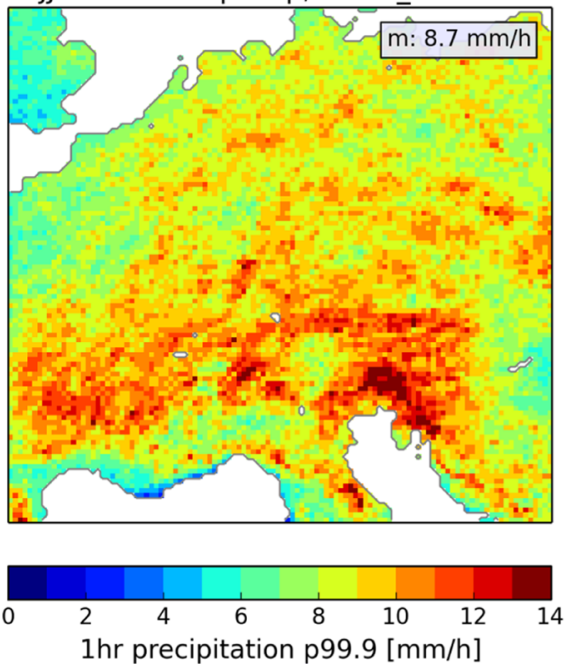

JJA P99.9 1hr precip, WRF12 MOC

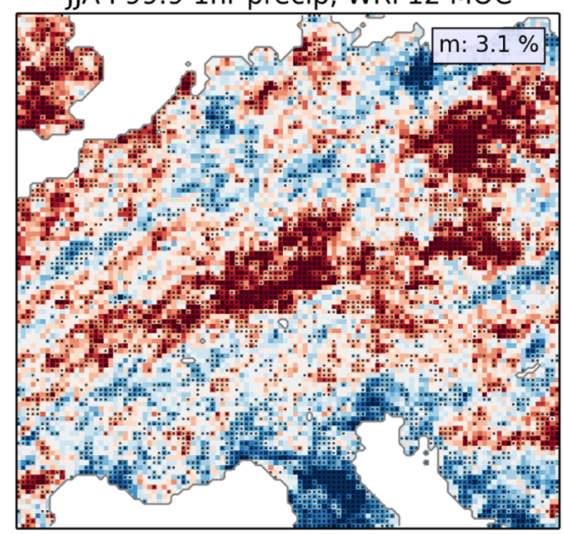

JJA P99.9 1hr precip, WRF3_12 MOC

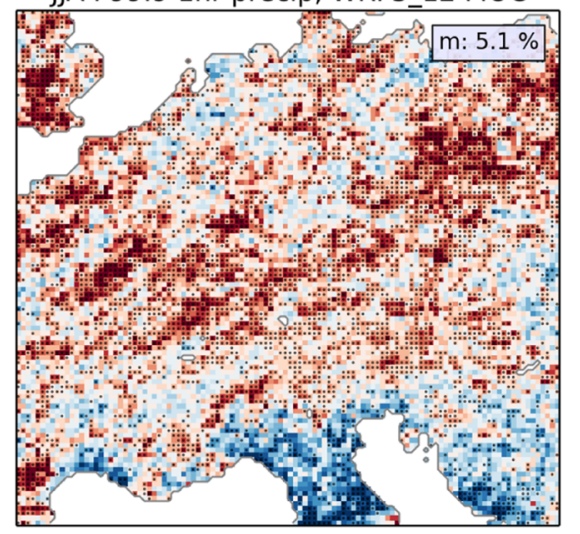

JJA P99.9 1hr precip, WRF12 EOC

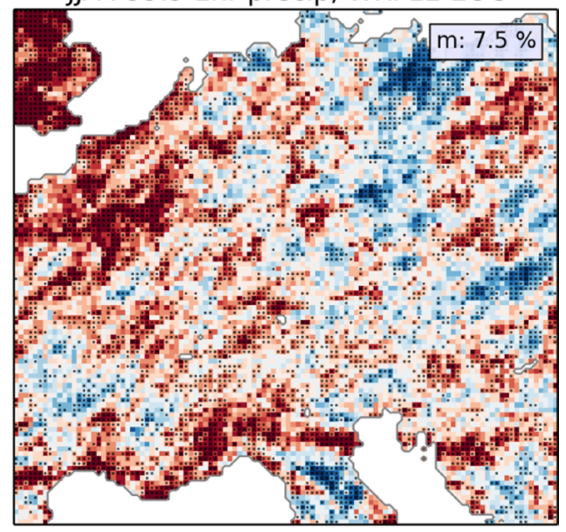

JJA P99.9 1hr precip, WRF3_12 EOC

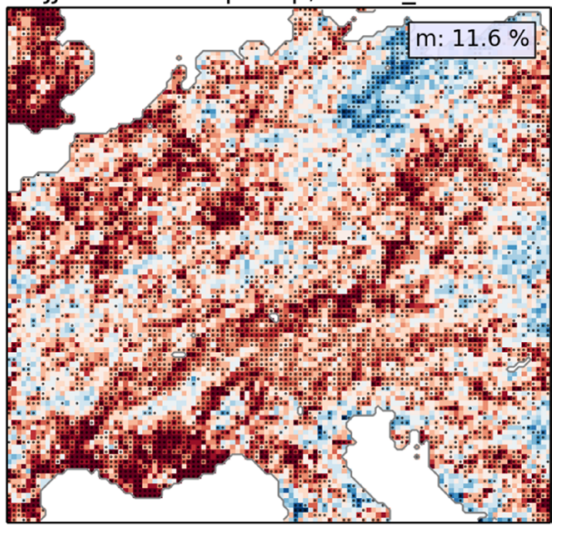

\begin{tabular}{rrrrrrrrr}
\hline-40 & -30 & -20 & -10 & 0 & 10 & 20 & 30 & 40
\end{tabular}

1hr precipitation p99.9 change [\%]
Fig. 8 Hourly extreme precipitation sums (99.9th percentile) in summer (JJA) in CTRL simulation time period (left) and its relative change in MOC (middle) and EOC (right) for the WRF12 (upper row) and WRF3_12 (lower row). Domain mean changes are indicated in the top right corner. Dots highlight significant changes (0.05 level) 

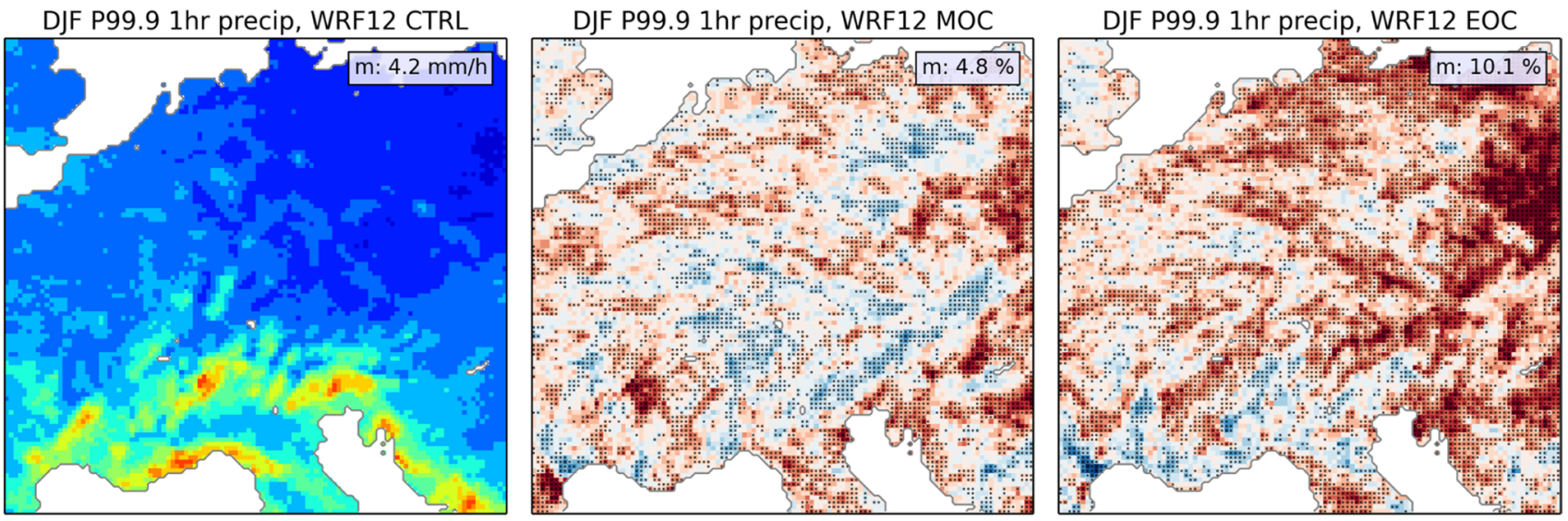

DJF P99.9 1hr precip, WRF3 12 CTRL

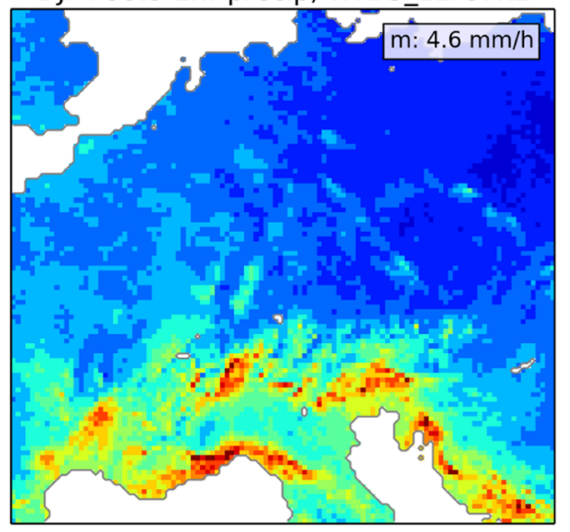

DJF P99.9 1hr precip, WRF3_12 MOC

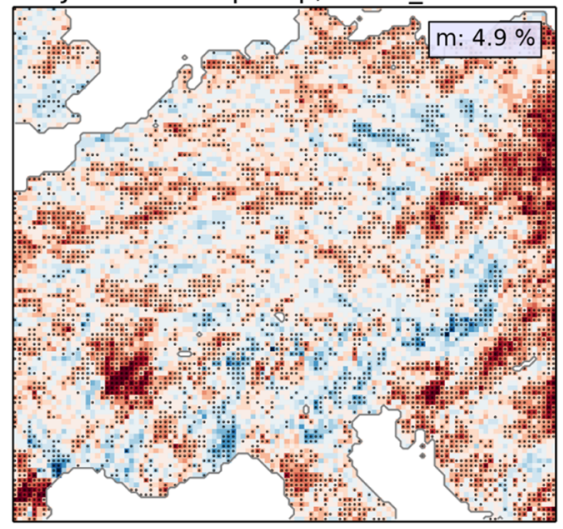

DJF P99.9 1hr precip, WRF3_12 EOC
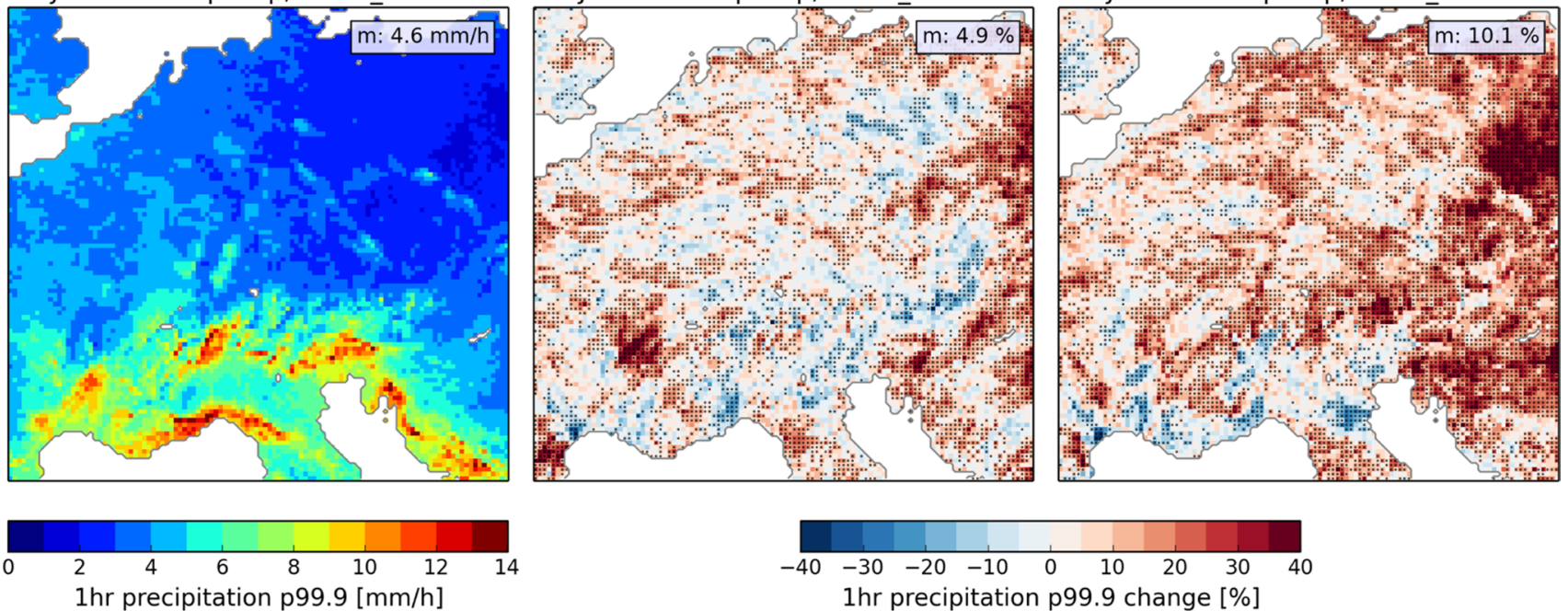

$\begin{array}{lllllllll}-40 & -30 & -20 & -10 & 0 & 10 & 20 & 30 & 40\end{array}$

$1 \mathrm{hr}$ precipitation p99.9 change [\%]

Fig. 9 Hourly extreme precipitation sums (99.9th percentile) in winter (DJF) in CTRL simulation time period (left) and its relative change in MOC (middle) and EOC (right) for the WRF12 (upper

mean precipitation (see Fig. 7) seems to manifest itself also in extreme precipitation.

The intensity distribution of hourly precipitation sums for CTRL, MOC and EOC differ between WRF12 and WRF3_12 (Fig. 10) with more light and moderate precipitation in WRF12 and more heavy precipitation in WRF3_12. This difference becomes larger in MOC and EOC; while the frequency of light and moderate precipitation further decreases in WRF12 and WRF3_12, the increase in heavy precipitation frequency is larger in WRF3_12.

This behavior is also confirmed by the domain averaged percentage change of hourly precipitation percentiles for MOC and EOC with respect to CTRL in summer (Fig. 11a). For MOC, WRF12 and WRF3_12 simulate an increase for percentiles higher than 99.5 and 99.7, respectively, of up to $+10 \%$ for percentiles higher than 99.99, while the lower percentiles are reduced. For EOC, WRF3_12 increases more rapidly to higher positive row) and WRF3_12 (lower row). Domain mean changes are indicated in the top right corner. Dots highlight significant changes (0.05 level)

changes reaching $+20 \%$ for the 99.99 th percentile. The decrease in mean precipitation (Fig. 6) is caused by less light and moderate hourly precipitation rates below the 99th percentile. In WRF12 the trend to stronger future increase for higher percentiles is less pronounced.

The WRF3 simulations for summer reach the $\mathrm{C}-\mathrm{C}$ scaling rate of $7 \% \mathrm{~K}^{-1}$ for MOC (EOC) at the 99.94th (99.95th) percentile, for WRF12 around the 99.98th percentile (Fig. 11b); both simulations show a super-adiabatic scaling exceeding $10 \% \mathrm{~K}^{-1}$ above the 99.99th percentile.

In line with the changes in extreme hourly precipitation, changes in extreme daily precipitation in summer reveal a larger increase for the $3 \mathrm{~km}$ compared to the $12 \mathrm{~km}$ simulation (data not shown). However, the scaling rates for the 99.9th percentile of daily precipitation (about one event in 12 seasons) are in the range of $\mathrm{C}-\mathrm{C}$ scaling for WRF3_12 $\left(6 \% \mathrm{~K}^{-1}\right)$ and lower than $\mathrm{C}-\mathrm{C}$ scaling for WRF12 (4\% $\left.\mathrm{K}^{-1}\right)$. 


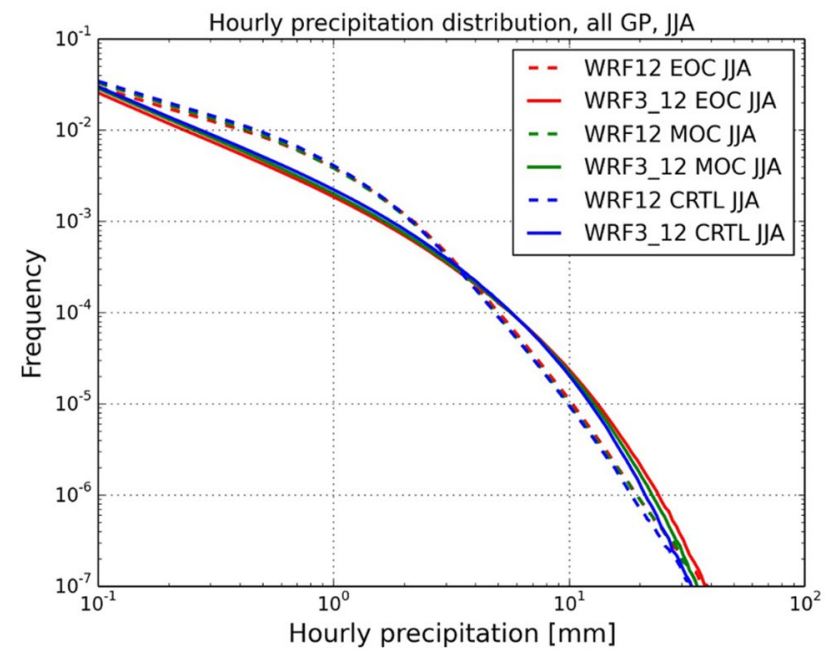

Fig. 10 Intensity distribution of hourly precipitation in summer (JJA) taking all domain grid points (GP) into account. WRF12 is indicated by dashed lines and WRF3_12 by solid lines. Colors indicate the 12 year simulation time periods CTRL (blue), MOC (green) and EOC (red)

Both simulations agree in the future change in heavy and extreme precipitation in winter; both show an increase of $5 \%(9 \%)$ for MOC (EOC) for the percentile range from 98th to 99.98 th (Fig. 11c). Unlike in summer the scaling rates remain below $5 \% \mathrm{~K}^{-1}$ and are projected to even decrease for extreme precipitation percentiles (> P99.9) (Fig. 11d).

\subsection{Projected temperature-extreme precipitation scaling}

For all time slices, current (CTRL), mid- (MOC) and endof-century (EOC) 12 and $3 \mathrm{~km}$ resolution runs yield constant scaling rates for the temperature range from 2 to $18{ }^{\circ} \mathrm{C}$ (Fig. 12a). While WRF3_12 shows a C-C scaling of 7\% $\mathrm{K}^{-1}$, the scaling rate in WRF12 is slightly smaller $(\sim 5.7 \%$ $\mathrm{K}^{-1}$ ), which is consistent with the results from the evaluation period as is the drop to negative scaling rates for high temperatures. For MOC and EOC the scaling curves are shifted to higher temperatures approximately parallel to the $7 \% \mathrm{~K}^{-1}$ scaling line; thus the drop of the scaling rate due to the transition to moisture limited regimes starts at higher temperatures and accordingly higher P99 ${ }_{\text {dmax }}$ precipitation. This is in good agreement with results by Prein et al. (2016a, b) for the contiguous US.

The shift of the scaling curves parallel to the $\mathrm{C}-\mathrm{C}$ scaling lines, while retaining their individual shapes for the future climate, is also found for the individual climate sub-regions (Fig. 12b-f). For lowlands and uplands, the increase to super-adiabatic scaling starts in the convection-permitting runs above $10{ }^{\circ} \mathrm{C}$ while the $12 \mathrm{~km}$ runs stick with a constant scaling rate of $7 \% \mathrm{~K}^{-1}$ also for higher temperatures. For northern Italy the T-P99 $9_{\text {dmax }}$ scaling for the $3 \mathrm{~km}$ runs is slightly below $7 \% \mathrm{~K}^{-1}$ for temperatures up to $16{ }^{\circ} \mathrm{C}$, then increases to super-adiabatic scaling until $20^{\circ} \mathrm{C}$ in the control period, where it drops to negative scaling rates; for $\mathrm{MOC}$ and EOC this drop shifts to 21 and $22{ }^{\circ} \mathrm{C}$, respectively. For southern France results are similar, but the shapes of the scaling curves are less coherent for the different time slices probably due to the small subdomain and larger variability.

Consistent with the evaluation results, scaling curves for WRF12 are overall flatter for all sub-regions and miss a transition to super-adiabatic scaling. But the shift of the scaling curves in warmer climates (MOC, EOC) with higher temperatures and stronger peak precipitation is also apparent. However, the shift does not follow the C-C scaling trajectory as clearly compared to the $3 \mathrm{~km}$ runs. When averaged over the whole domain (Fig. 12a), the shift follows a lower than $\mathrm{C}-\mathrm{C}$ scaling rate, while the results for the sub-regions are too noisy due to the small shifts.

It is important to note that already for the moderate warming signal in the RCP4.5 scenario used here (about $1.5 \mathrm{~K}$ in MOC and about $2 \mathrm{~K}$ in EOC) compared to RCP8.5 scenarios used in other studies with warmings of 4-5 K (e.g. in Kendon et al. 2014; Ban et al. 2015; Prein et al. 2016a, b), extreme precipitation clearly increases in our WRF simulations.

\section{Summary and conclusion}

In this study we investigate for the first time for Central Europe the added value of convection-permitting regional climate simulations for the representation of extreme precipitation and temperature-precipitation scaling in the current and RCP4.5-projected climate runs. Our results for 12 and $3 \mathrm{~km}$ resolution clearly differ for summer in structure, diurnal cycle and mean precipitation amount. In winter, differences are smaller and mostly related to orography. The comparison of 9-years ERA-Interim-driven simulations against rain gauges in Germany and Switzerland show, that the $3 \mathrm{~km}$ simulations better reproduce observed hourly precipitation intensity distributions. Too frequent light precipitation results in a wet bias in both simulations, which is however reduced in the $3 \mathrm{~km}$ resolutions runs in summer. The frequencies of heavy and extreme hourly precipitation are underestimated in the $12 \mathrm{~km}$ runs and much better captured in the $3 \mathrm{~km}$ runs, although extreme precipitation events are overestimated in mountainous regions, which might also result from uncertainties in the observations (Ban et al. 2014). While the $3 \mathrm{~km}$ runs also better represent the diurnal cycle of precipitation, the improvement in phase and amplitude in the convection-permitting simulation is less compared to other studies (e.g. Kendon et al. 2012; Ban et al. 2014; Fosser et al. 2015). Largest 

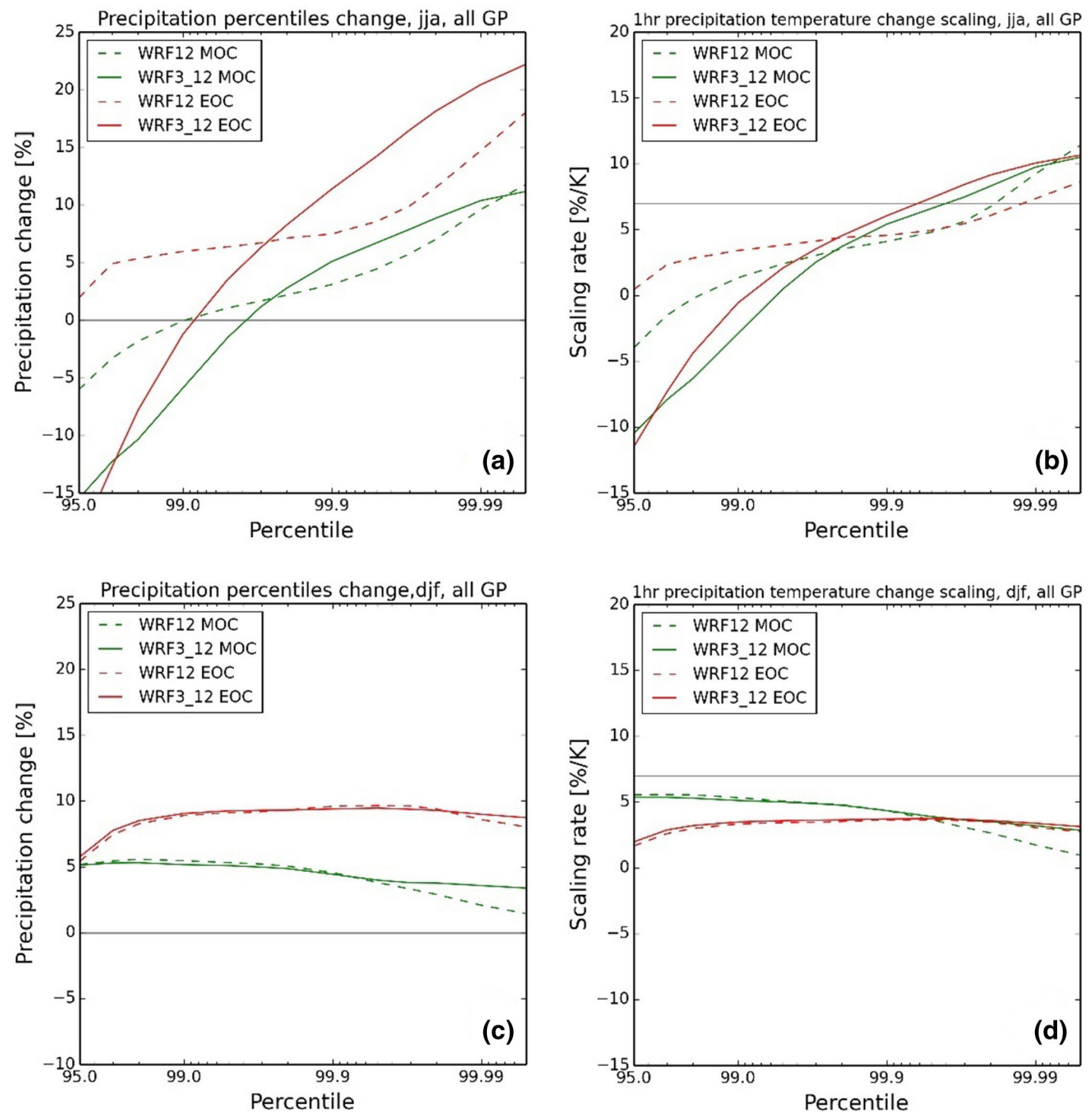

Fig. 11 a, c Percentage change of hourly precipitation percentiles in MOC (green) and EOC (red) as difference to CTRL for both WRF12 (dashed) and WRF3_12 (solid) based on the spatial average of all grid point (GP) relative changes for summer (a) and winter (c). b, d

differences between both resolutions, also when compared to observations, are found in mountainous regions, where onset and daily maximum are simulated too early and too strong, respectively, especially in the $12 \mathrm{~km}$ simulation. This is consistent with findings by Langhans et al. (2013) and Prein et al. (2013). They however suggest that the poor

Scaling rate of percentage change of hourly precipitation percentiles normalized by local mean temperature change in MOC (green) and EOC (red) as difference to CTRL based on the spatial average of all grid point relative scaling rates for summer $(\mathbf{b})$ and winter $(\mathbf{d})$

performance of the coarse simulation is caused by the convection scheme rather than by the unresolved small-scale topography. A detailed investigation of this issue will be part of a follow-up sensitivity study. Overall, results are in line with findings on convection permitting climate 
Fig. 12 Temperature-extreme precipitation scaling in WRF12 (dashed) and WRF3_12 (solid) for simulation time period CTRL (blue), MOC (green) and EOC (red) for different regions. For each grid point (GP) daily maximum hourly precipitation is discretized into one-degree bins of daily mean temperature. To account for different altitudes, temperature is extrapolated to sea level by assuming a lapse rate of $0.0065 \mathrm{Km}^{-1}$ first. For each temperature bin with a sample size larger than 100 the 99th percentile of the precipitation values $\left(\mathrm{P} 99_{\mathrm{dmax}}\right)$ is calculated and averaged over all grid points in the particular region. Light blue, grey and pink dashed lines indicate a scaling of $3.5,7$ and $10.5 \% \mathrm{~K}^{-1}$ (according 0.5, 1 and 1.5 times $\mathrm{C}-\mathrm{C}$ scaling rate), respectively
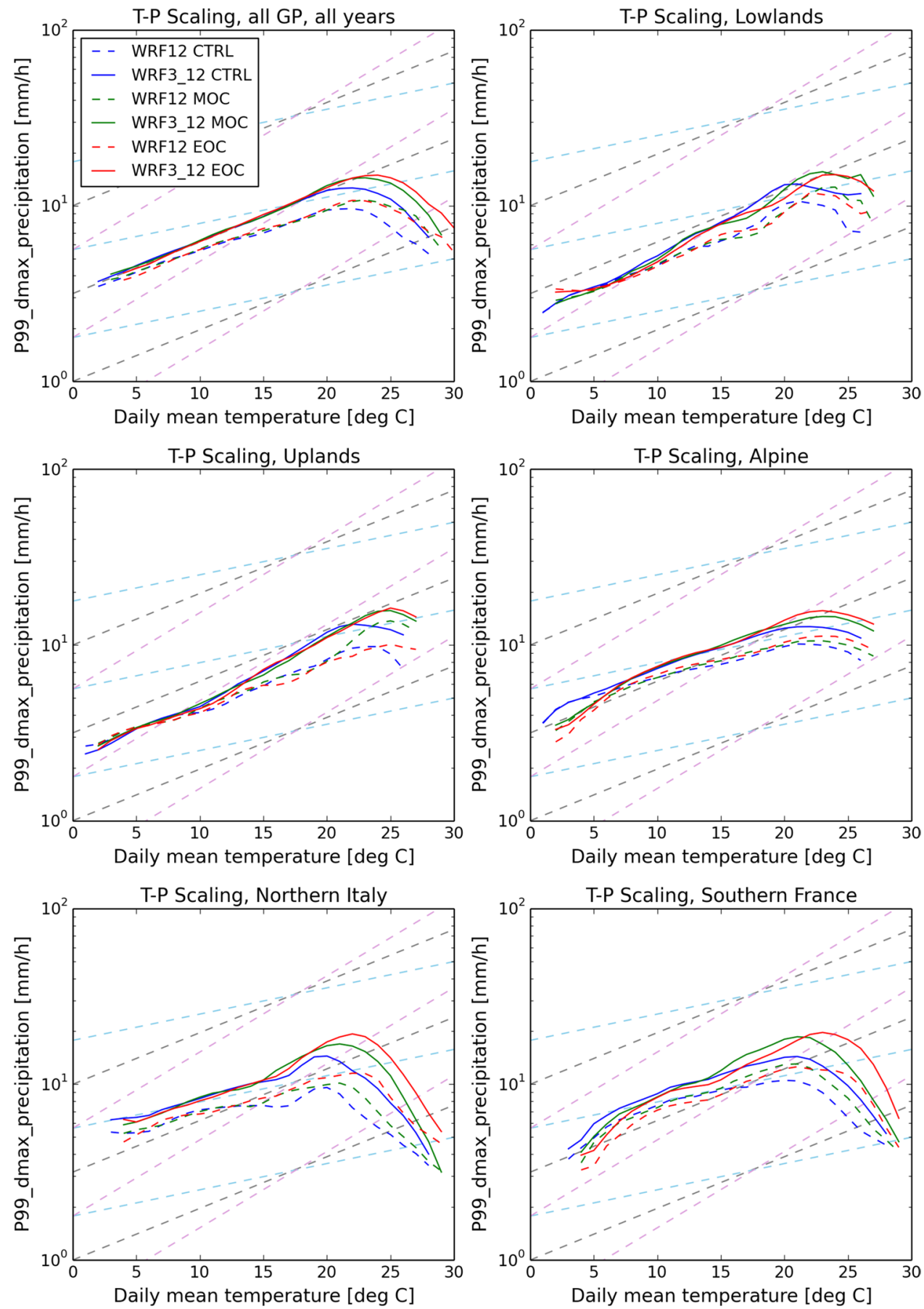

simulations summarized by (Prein et al. 2015) and confirm the added value of convection-permitting climate simulations.

In addition, the observed scaling of extreme precipitation $\left(\mathrm{P} 99_{\mathrm{dmax}}\right)$ with daily mean temperature is better reproduced by the convection-permitting simulations. The $12 \mathrm{~km}$ simulations miss the observed increase from a $\mathrm{C}-\mathrm{C}$ scaling rate $\left(\sim 7 \% \mathrm{~K}^{-1}\right)$ to a super-adiabatic scaling rate $\left(\sim 10 \% \mathrm{~K}^{-1}\right)$ at temperatures above $11^{\circ} \mathrm{C}$ in accordance with the underestimation of the frequency of summer heavy and extreme precipitation events. The stronger scaling rate, related to dominant convective precipitation in this temperature range (Berg et al. 2013), is better captured by the explicit simulation of convection in WRF3. However, both simulations reproduce the observed drop of scaling rates at high temperatures caused by moisture limited conditions. Scaling-rate curves differ between subregions as shown, e.g., by an earlier drop of the scaling rate in southern France and northern Italy. 
We further analyze projected changes of precipitation statistics for mid-of-the-century (MOC, 2038-2050) and end-of-the-century (EOC, 2088-2100) with respect to a control period (CTRL, 1993-2005) derived from downscaling global climate runs based on a RCP4.5 scenario. Both downscaling simulations suggest slight decreases of mean summer precipitation over Central Europe for MOC and EOC, respectively, while heavy and extreme hourly precipitation intensities increase in particular for the higher percentiles. The latter tendency is stronger in the $3 \mathrm{~km} \mathrm{simu-}$ lations leading to larger differences between the frequencyintensity distributions with progressing climate change. We find super-adiabatic scaling $\left(>7 \% \mathrm{~K}^{-1}\right)$ for extreme hourly precipitation above the 99.95 th percentile which is in line with similar studies for the UK (Kendon et al. 2014) and larger than for the Alpine region by Ban et al. (2015), who did not find super-adiabatic intensity increases. Differences might result from different models, resolutions and regions considered. Also, different calculations of extreme precipitation indices including spatial averaging strategies may also lead to different results (Schär et al. 2016). When scaling future changes of extreme precipitation by seasonal mean temperature changes [as conventionally done e.g. by Kendon et al. (2014), Gorman (2015), Ban et al. (2015) and Prein et al. (2016b)], the true scaling rates are—in our view—only approximated since the temperature for days with extreme precipitation events will differ. Wang et al. (2017) showed that scaling unconditional extreme daily precipitation (defined with no regard to temperature) with mean seasonal temperature may yield a spuriously low scaling rate $(2-5 \%$ $\mathrm{K}^{-1}$ ), that is not directly related to any specific process or to $\mathrm{C}-\mathrm{C}$ scaling.

Temperature-extreme precipitation scaling curves in the present and the future climate in several sub-regions shift to higher temperatures and higher peak extreme precipitation in MOC and EOC approximately following a $7 \% \mathrm{~K}^{-1}(\mathrm{C}-\mathrm{C})$ trajectory while keeping the typical shape of the individual scaling curves with a drop of scaling rates at high temperatures in moisture limited conditions. Our results for Europe are in line with findings by Prein et al. (2016a, b) for different climate regions in the contiguous US. As suggested by Westra et al. (2014), Ban et al. (2015), Prein et al. (2016a, b) and Wang et al. (2017) present-day scaling rates cannot be simply extrapolated into the future.

Acknowledgements The authors gratefully acknowledge the computing time Granted by the JARA-HPC Vergabegremium and VSR commission on the super-computer JURECA at Forschungszentrum Jülich through compute time Project JJSC15. Work has been sponsored by the CRC/TR32 project "Patterns in Soil-Vegetation-Atmosphere Systems: Monitoring, Modelling and Data Assimilation" funded by the German Research Foundation (DFG), through a research and development cooperation on hydrometeorology between the Federal Institute of Hydrology, Koblenz, Germany, and the Meteorological Institute, University of Bonn, Bonn, Germany and through the EC-funded
HORIZON 2020 project eLTER (GA: 654359-H2020 INFRAIA call 2014-2015).

Open Access This article is distributed under the terms of the Creative Commons Attribution 4.0 International License (http://creativeco mmons.org/licenses/by/4.0/), which permits unrestricted use, distribution, and reproduction in any medium, provided you give appropriate credit to the original author(s) and the source, provide a link to the Creative Commons license, and indicate if changes were made.

\section{References}

Allen MR, Ingram WJ (2002) Constraints on future changes in climate and the hydrologic cycle. Nature 419:224. https://doi.org/10.1038/ nature 01092

Ban N, Schmidli J, Schaer C (2014) Evaluation of the convectionresolving regional climate modeling approach in decade-long simulations. J Geophys Res Atmos 119:7889-7907. https://doi. org/10.1002/2014JD021478

Ban N, Schmidli J, Schär C (2015) Heavy precipitation in a changing climate: Does short-term summer precipitation increase faster? Geophys Res Lett 42:1165-1172. https://doi.org/10.1002/2014G L062588

Berg P, Moseley C, Haerter JO (2013) Strong increase in convective precipitation in response to higher temperatures. Nat Geosci 6:181-185. https://doi.org/10.1038/ngeo1731

Brisson E, Van Weverberg K, Demuzere M et al (2016) How well can a convection-permitting climate model reproduce decadal statistics of precipitation, temperature and cloud characteristics? Clim Dyn 47:3043-3061. https://doi.org/10.1007/s00382-016-3012-z

Brockhaus P, Lüthi D, Schär C (2008) Aspects of the diurnal cycle in a regional climate model. Meteorol Zeitschrift 17:433-443. https ://doi.org/10.1127/0941-2948/2008/0316

Chan SC, Kendon EJ, Roberts NM et al (2016) Downturn in scaling of UK extreme rainfall with temperature for future hottest days. Nat Geosci 9:24-28

Dee DP, Uppala SM, Simmons a. J, et al (2011) The ERA-Interim reanalysis: configuration and performance of the data assimilation system. Q J R Meteorol Soc 137:553-597. https://doi.org/10.1002/ qj. 828

Dirmeyer PA, Cash BA, Kinter JL et al (2012) Simulating the diurnal cycle of rainfall in global climate models: resolution versus parameterization. Clim Dyn 39:399-418. https://doi.org/10.1007/ s00382-011-1127-9

Drobinski P, Silva N, Da, Panthou G et al (2016) Scaling precipitation extremes with temperature in the Mediterranean: past climate assessment and projection inanthropogenic scenarios. Clim Dyn 1-21. https://doi.org/10.1007/s00382-016-3083-x

Ek MB, Mitchell KE, Lin Y et al (2003) Implementation of Noah land surface model advances in the National Centers for Environmental Prediction operational mesoscale Eta model. J Geophys Res Atmos. https://doi.org/10.1029/2002JD003296

Fosser G, Khodayar S, Berg P (2015) Benefit of convection permitting climate model simulations in the representation of convective precipitation. Clim Dyn 44:45-60. https://doi.org/10.1007/s0038 2-014-2242-1

García-Díez M, Fernández J, Vautard R (2015) An RCM multi-physics ensemble over Europe: multi-variable evaluation to avoid error compensation. Clim Dyn 45:3141-3156. https://doi.org/10.1007/ s00382-015-2529-x

Gorman PAO (2015) Precipitation extremes under climate change. pp 49-59. https://doi.org/10.1007/s40641-015-0009-3 
Grell GA, Dévényi D (2002) A generalized approach to parameterizing convection combining ensemble and data assimilation techniques. Geophys Res Lett 29:381-384. https://doi.org/10.1029/2002G L015311

Grell GA, Schade L, Knoche R et al (2000) Nonhydrostatic climate simulations of precipitation over complex terrain. J Geophys Res Atmos. https://doi.org/10.1029/2000JD900445

Hanel M, Buishand TA (2010) On the value of hourly precipitation extremes in regional climate model simulations. J Hydrol 393:265-273. https://doi.org/10.1016/j.jhydrol.2010.08.024

Hardwick Jones R, Westra S, Sharma A (2010) Observed relationships between extreme sub-daily precipitation, surface temperature, and relative humidity. Geophys Res Lett 37:1-5. https://doi. org/10.1029/2010GL045081

Hohenegger C, Brockhaus P, Schaer C (2008) Towards climate simulations at cloud-resolving scales. Meteorol ZEITSCHRIFT 17:383394. https://doi.org/10.1127/0941-2948/2008/0303

Hong S-Y, Dudhia J, Chen S-H (2004) A revised approach to ice microphysical processes for the bulk parameterization of clouds and precipitation. Mon Weather Rev 132:103-120. https://doi. org/10.1175/1520-0493(2004)132<0103:ARATIM>2.0.CO;2

Hong S-Y, Noh Y, Dudhia J (2006) A new vertical diffusion package with an explicit treatment of entrainment processes. Mon Weather Rev 2318-2341

Iacono MJ, Delamere JS, Mlawer EJ et al (2008) Radiative forcing by long-lived greenhouse gases: calculations with the AER radiative transfer models. J Geophys Res Atmos 113:2-9. https://doi. org/10.1029/2008JD009944

Jacob D, Petersen J, Eggert B et al (2013) EURO-CORDEX: new high-resolution climate change projections for European impact research. Reg Environ Chang 14:563-578. https://doi. org/10.1007/s10113-013-0499-2

Jones PW (1999) First- and second-order conservative remapping schemes for grids in spherical coordinates.Mon Weather Rev 127:2204-2210. https://doi. org/10.1175/1520-0493(1999)127<2204:FASOCR >2.0.CO;2

Katragkou E, García-Díez M, Vautard R et al (2014) Hindcast regional climate simulations within EURO-CORDEX: evaluation of a WRF multi-physics ensemble. Geosci Model Dev Discuss 7:6629-6675. https://doi.org/10.5194/gmdd-7-6629-2014

Kendon EJ, Roberts NM, Senior CA, Roberts MJ (2012) Realism of rainfall in a very high-resolution regional climate model. J Clim 25:5791-5806. https://doi.org/10.1175/JCLI-D-11-00562.1

Kendon EJ, Roberts NM, Fowler HJ et al (2014) Heavier summer downpours with climate change revealed by weather forecast resolution model. Nat Clim Chang 4:570-576

Knist S, Goergen K, Buonomo E et al (2017) Land-atmosphere coupling in EURO-CORDEX evaluation experiments. J Geophys Res Atmos 1-25. https://doi.org/10.1002/2016JD025476

Knote C, Heinemann GR (2010) Changes in weather extremes: assessment of return values using high resolution climate simulations at convection-resolving scale. Meteorol Zeitschrift 19:11-23. https ://doi.org/10.1127/0941-2948/2010/0424

Kotlarski S, Keuler K, Christensen OB et al (2014) Regional climate modeling on European scales: a joint standard evaluation of the EURO-CORDEX RCM ensemble. Geosci Model Dev 7:12971333. https://doi.org/10.5194/gmd-7-1297-2014

Langhans W, Schmidli J, Fuhrer O et al (2013) Long-term simulations of thermally driven flows and orographic convection at convection-parameterizing and cloud-resolving resolutions. J Appl Meteorol Climatol 52:1490-1510. https://doi.org/10.1175/ JAMC-D-12-0167.1

Lenderink G, van Meijgaard E (2008) Increase in hourly precipitation extremes beyond expectations from temperature changes. Nat Geosci 1:511-514. https://doi.org/10.1038/ngeo262

Lenderink G, Barbero R, Loriaux JM, Fowler HJ (2017) Super-Clausius-Clapeyron scaling of extreme hourly convective precipitation and its relation to large-scale atmospheric conditions. J Clim 30:6037-6052. https://doi.org/10.1175/JCLI-D-16-0808.1

Leutwyler D, Fuhrer O, Lapillonne X et al (2016) Towards Europeanscale convection-resolving climate simulations with GPUs: a study with COSMO 4.19. Geosci Model Dev 9:3393-3412. https ://doi.org/10.5194/gmd-9-3393-2016

Mass CF, Ovens D, Westrick K, Colle BA (2002) Does Increasing Horizontal Resolution Produce More Skillful Forecasts? Bull Am Meteorol Soc 83:407-430. https://doi. org/10.1175/1520-0477(2002)083<0407:DIHRPM > 2.3.CO;2

Prein AF, Gobiet A, Suklitsch M et al (2013) Added value of convection permitting seasonal simulations. Clim Dyn 41:2655-2677. https://doi.org/10.1007/s00382-013-1744-6

Prein AF, Langhans W, Fosser G et al (2015) A review on regional convection-permitting climate modeling: demonstrations, prospects,and challenges. Rev Geophys 53:323-361. https://doi. org/10.1002/2014RG000475

Prein AF, Gobiet A, Truhetz H et al (2016a) Precipitation in the EUROCORDEX $\$ \$ 0.11^{\wedge}\{$ |circ $\} \$ 0.11^{\circ}$ and $\$ \$ 0.44^{\wedge}\{$ |circ $\} \$ 0.44^{\circ}$ simulations: high resolution, high. Benefits? Clim Dyn 46:383412. https://doi.org/10.1007/s00382-015-2589-y

Prein AF, Rasmussen RM, Ikeda K et al (2016b) The future intensification of hourly precipitation extremes. Nat Clim Chang 1:1-6. https ://doi.org/10.1038/nclimate3168

Richard E, Buzzi A, Zaengl G (2007) Quantitative precipitation forecasting in the Alps: the advances achieved by the mesoscale alpine programme. Q J R Meteorol Soc 133:831-846. https://doi. org/10.1002/qj.65

Schär C, Ban N, Fischer EM et al (2016) Percentile indices for assessing changes in heavy precipitation events. Clim Change 137:201216. https://doi.org/10.1007/s10584-016-1669-2

Skamarock W, Klemp JB, Dudhia J et al (2008) A description of the advanced research WRF Version 3. NCAR Tech Note. https://doi. org/10.5065/D68S4MVH

Stevens B, Giorgetta M, Esch M et al (2013) Atmospheric component of the MPI-M earth system model: ECHAM6. J Adv Model Earth Syst 5:146-172. https://doi.org/10.1002/jame.20015

Trenberth KE, Dai A, Rasmussen RM, Parsons DB (2003) The changing character of precipitation. Bull Am Meteorol Soc 84:1205$1217+1161$. https://doi.org/10.1175/BAMS-84-9-1205

Utsumi N, Seto S, Kanae S et al (2011) Does higher surface temperature intensify extreme precipitation? Geophys Res Lett 38:1-5. https://doi.org/10.1029/2011GL048426

Wang G, Wang D, Trenberth KE et al (2017) The peak structure and future changes of the relationships between extreme precipitation and temperature. Nat Clim Chang 7:268-274. https://doi. org/10.1038/nclimate3239

Westra S, Fowler HJ, Evans JP et al (2014) Future changes to the intensity and frequency of short-duration extreme rainfall. Rev Geophys 52:522-555. https://doi.org/10.1002/2014RG000464 